\title{
A framework for implementing holistic and integrated life cycle sustainability assessment of regional bioeconomy
}

\author{
Walther Zeug ${ }^{1}\left(\mathbb{D} \cdot\right.$ Alberto Bezama $^{1} \cdot$ Daniela Thrän ${ }^{1,2}$
}

Received: 10 March 2021 / Accepted: 27 September 2021 / Published online: 22 October 2021

(c) The Author(s) 2021

\begin{abstract}
Purpose Currently, social, environmental, and economic risks and chances of bioeconomy are becoming increasingly a subject of applied sustainability assessments. Based on life cycle assessment (LCA) methodology, life cycle sustainability assessment (LCSA) aims to combine or integrate social, environmental, and economic assessments. In order to contribute to the current early stage of LCSA development, this study seeks to identify a practical framework for integrated LCSA implementation.

Methods We select possible indicators from existing suitable LCA and LCSA approaches as well as from the literature, and allocate them to a sustainability concept for holistic and integrated LCSA (HILCSA), based on the Sustainable Development Goals (SDGs). In order to conduct a practical implementation of HILCSA, we choose openLCA, because it offers the best current state and most future potential for application of LCSA. Therefore, not only the capabilities of the software and databases, but also the supported methods of life cycle impact assessments (LCIA) are evaluated regarding the requirements of the indicator set and goal and scope of future case studies.

Results and discussion This study presents an overview of available indicators and LCIAs for bioeconomy sustainability assessments as well as their link to the SDGs. We provide a practical framework for HILCSA of regional bioeconomy, which includes an indicator set for regional (product and territorial) bioeconomy assessment, applicable with current software and databases, LCIA methods and methods of normalization, weighting, and aggregation. The implementation of HILCSA in openLCA allows an integrative LCSA by conducting all steps in a single framework with harmonized, aggregated, and coherent results. HILCSA is capable of a sustainability assessment in terms of planetary boundaries, provisioning system and societal needs, as well as communication of results to different stakeholders.

Conclusions Our framework is capable of compensating some deficits of S-LCA, E-LCA, and economic assessments by integration, and shows main advantages compared to additive LCSA. HILCSA is capable of addressing 15 out of 17 SDGs. It addresses open questions and significant problems of LCSAs in terms of goal and scope, LCI, LCIA, and interpretation. Furthermore, HILCSA is the first of its kind actually applicable in an existing software environment. Regional bioeconomy sustainability assessment is bridging scales of global and regional effects and can inform stakeholders comprehensively on various impacts, hotspots, trade-offs, and synergies of regional bioeconomy. However, significant research needs in LCIAs, software, and indicator development remain.
\end{abstract}

Keywords Bioeconomy $\cdot$ Sustainability assessment · SDGs $\cdot$ Life cycle assessment $\cdot$ Life cycle sustainability assessment · Life cycle impact assessment $\cdot$ openLCA

Communicated by Guido W. Sonnemann

Walther Zeug

walther.zeug@ufz.de

Alberto Bezama

alberto.bezama@ufz.de

Daniela Thrän

daniela.thraen@ufz.de
1 Department of Bioenergy, Helmholtz-Centre for Environmental Research (UFZ), 04318 Leipzig, Germany

2 Bioenergy Systems Department, Deutsches Biomasseforschungszentrum (DBFZ), 04318 Leipzig, Germany 


\section{Introduction}

Decoupling human well-being from environmental impacts as well as the fulfillment of societal needs by a socially just and sustainable provisioning system is and will be the major challenge to avoid a socioecological crisis. We understand the emerging bioeconomy as a provisioning system linking social outcomes and renewable resources by innovative technologies. Bioeconomy comprises both physical and social systems, mediating the relationship between planetary boundaries and societal needs by economic activities of physical infrastructures. Thus, a sustainable bioeconomy should be assessed with regard to its potential to provide a good life for all within planetary boundaries (Zeug et al. 2020; O’Neill et al. 2018). So far, attempts into such assessments are focused on achieving gains in ecotechnological efficiency. However, though improvements in efficiencies are necessary, they are not sufficient in designing a sustainable bioeconomy. Instead, societal and economic transformations entailing bioeconomy are necessary (Ramcilovic-Suominen and Pülzl 2018; Hausknost et al. 2017; Bezama et al. 2019). This consideration actually implies the need for a double decoupling, i.e., decoupling of the increasing satisfaction of societal needs from an otherwise ever greater production of material goods and services as well as decoupling of the production of goods and services from growing negative ecological, social, and economic effects.

In order to accommodate for this complexity of demands on social, ecological, and economic sustainability (holistic sustainability), the Sustainable Development Goals (SDGs) provide measurable and normative objectives for bioeconomy assessments (Zeug et al. 2020, 2019; Linser and Lier 2020; Calicioglu and Bogdanski 2021). By stakeholder participation, we identified and quantified relevances of SDGs for bioeconomy assessments in Germany (in descending order): ending hunger (SDG 2); sustainable consumption and production (SDG 12); terrestrial ecology (SDG 15); oceanic ecology (SDG 14); water and sanitation (SDG 6); climate change (SDG 13); affordable and clean energy (SDG 7); industrialization, innovation, and infrastructure (SDG 9); and no poverty (SDG 1) (Zeug et al. 2019). Nearly all of the named SDGs are developing problematically-hunger is rising again, consumption and productions patterns remain unchanged at a global level, the global material footprint is rapidly growing, and economic output and natural resource use are far from being decoupled (UN 2019; Zeug et al. 2020).

This shows that looking at a specific bioeconomy, in this case Germany, implies to look at its global effects. For this reason, the two depictions of bioeconomy, a new societal and economic development path as well as an improvement in specific products, should be merged and consequently the two main scales of bioeconomy sustainability assessment as well: a territorial (macro) and a product level (micro) (Bracco et al. 2019). However, the SDGs and their individual sub-goals cannot be applied directly to regional bioeconomy, rather they represent a general global political agenda (Zeug et al. 2019; Lyytimaki et al. 2020; UNEP 2020). So, they need to be applied and adapted by means of specific indicators. A particular focus has to be on different kinds of indicators, what bioeconomy aspects they are able to represent, and also how more abstract societal questions, like bioeconomy as a societal change, can be addressed by them. However, although there are no sets of indicators for merging a territorial and product scale to a regional scale (Linser and Lier 2020), a comprehensive review of possible indicators was presented in the FAO Indicators to Monitor and Evaluate the Sustainability of bioeconomy (Bracco et al. 2019). The latter study provides a suitable basis for our analysis.

A measurement and evaluation of sustainability, mainly at product level, is the central motivation of different approaches to life cycle assessments (LCAs). Within the broad spectrum of LCA approaches and methods, LCSAs as the most recent development are a combination or integration of social LCA (S-LCA), environmental LCA (E-LCA), and life cycle costing (LCC). As a relatively new field, LCAs and LCSAs are considered to be used for regional sustainability assessments (Balkau and Bezama 2019). This scope on regional bioeconomy as provisioning systems on a meso level, which we apply in the following, means to take up concrete production processes and imbedding them in their specific regional context with regard to global effects (Zeug et al. 2020). Regions differ in their socioeconomic and environmental conditions, with corresponding differences in strategies, research, and implementation. This implies that in future research we need especially meta- and sector-wide studies of regional and respective global effects and possible interventions (Ingrao et al. 2018; Fröhling and Hiete 2020).

However, LCSAs face the most significant problems, and in terms of indicators, impact assessment methods, normalization, weighting, aggregation as well as harmonization, many questions are open-but they also seem to have the most potential of empirical sustainability assessments (Balkau and Sonnemann 2017; Ingrao et al. 2018; Guinée 2016; Onat et al. 2017; Urban e al. 2018; OECD 2018). Currently, there are two main definitions or understandings of LCSA; on the one hand, the widely known combining and additive scheme (LCSA $=\mathrm{E}-\mathrm{LCA}+\mathrm{LCC}+\mathrm{S}$-LCA) (Klöpffer 2008)_based on the three-pillar approach, three different methods have to be standardized, harmonized, synchronized, and then combined. On the other hand, a far less established vision of an integrative approach (Guinée et al. 2011)—within 
a common sustainability concept, social, ecological, and economic aspects-should be integrated into a unified assessment and methodical framework. We evaluated the underlying assumptions and sustainability concepts of those two approaches as well as respective consequences for life cycle inventory (LCI), life cycle impact assessment (LCIA), and interpretation (Zeug et al. 2020). In this previous work, we discussed extensively a variety of approaches based on existing reviews, as well as their pros and cons, which we not repeat in this study. Due to its more consistent character, we considered integrated LCSA as most appropriate for holistic sustainability assessments (cf. Sala et al. 2012b, a; Keller et al. 2015). We also set the conceptual basis and sustainability framework of our holistic and integrated LCSA (HILCSA), by introducing the SDGs and the transdisciplinary grounded theory of Societal Relations to Nature. Societal needs, provisioning systems, and ecological boundaries are not seen as separate entities, but rather as facets of one and the same object-industrial metabolisms and their provisioning systems, like bioeconomy (Zeug et al. 2020).

Recent comprehensive reviews, however, show that most LCSA approaches more or less follow the additive and not integrated scheme, yet (Costa et al. 2019; D'Amato et al. 2020; Wulf et al. 2019; Fauzi et al. 2019; Zimek et al. 2019; Troullaki et al. 2021). In sustainability concepts and LCSA in general, there are significant gaps regarding indicator sets, frameworks and software for implementation, databases, LCIAs, and applications of integrated but also additive LCSAs. As well as especially S-LCA and LCC are still under development and not robustly applicable (Wulf et al. 2018; Keller et al. 2015), which is likewise true for additive and integrated LCSA. However, integrative LCSA demands for even more consistent and mature methodologies as well as software implementation than the additive scheme does, which might be the main reason why additive LCSA is mainly used. A lack of harmonization and limited comparability is the consequence, and a variety of impact categories differ across studies and methods (Costa et al. 2019). Within S-LCA the selection of indicators, LCIAs and handling of (semi-)qualitative and quantitative indicators and results propose big challenges (Wulf et al. 2019; Guinée 2016). In LCC, questions arise on how to implement socioeconomic, mesoeconomic, and macroeconomic aspects beyond traditional microeconomic LCC (Zimek et al. 2019). In this regard, data availability and moreover existence of applicable databases are major constraints (Costa et al. 2019; Wulf et al. 2019). Which is particularly important, when it comes to more regionalized and spatially explicit datasets in order to improve quality of results (Fauzi et al. 2019). Having said that, it is just as important as taking planetary boundaries and global effects into account in LCSA by appropriate LCIAs (Chandrakumar and McLaren 2018b, a; Chandrakumar et al. 2018). In recent years, significant developments were made, especially in context of the European Commission-Joint Research Centre (EC-JRC) to integrate planetary boundaries and environmental footprints into E-LCA in order to allow mesoeconomic and macroeconomic assessments and conclusions by sector and product-specific bottom-up approaches (Sala and Castellani 2019; Sala et al. 2020; Bjørn et al. 2020; Robert et al. 2020; Fazio et al. 2018). Most of the shown issues go hand in hand with implementation of LCA and LCSA within a software environment, since development of LCA software, databases, and LCIA methods is mutually connected and depends on each other, as well as most LCA practitioners depend on them (Fritter et al. 2020). There are further practical challenges in the operationalization of LCSA and integrated LCSA, e.g., definition of coherent system boundaries, methods to conduct sensitivity and uncertainty analysis (Costa et al. 2019), rebound effects (Guinée 2016), trade-offs, biased decision making between social, economic, and environmental aspects (Fauzi et al. 2019) among others. In this study, we focus on the following research questions for setting up a practical framework for HILCSA:

What are criteria and aspects for implementation and operationalization of HILCSA for bioeconomy regions? What should a scope, goal, interpretation, and most importantly an LCI and LCIA look like for this?

\section{Methodology}

First, the methodical point of departure is our previously developed HILCSA sustainability framework (Zeug et al. 2020) (Fig. 1, (1)). In this framework, we extensively discussed the background theory on sustainability and LCA as well as integrated social, ecological, and economic aspects assigned to specific SDGs and their corresponding sub-goals (Table 1). To transfer this theory and sustainability framework to LCA practice, in this study on implementation and operationalization of HILCSA, we followed the integrated LCSA approach, i.e., integration of these aspects and LCA methods in a common goal and scope, LCI, LCIA, results, and interpretation. There are currently two general methodical approaches for linking SDGs and LCA: (i) qualitatively linking existing LCA indicators and midpoints to SDGs as endpoints and (ii) quantitatively linking SDGs as midpoints to LCA indicators and endpoints (Weidema and Goedkoop 2019). For this research, we are following (i) implying to rather use existing LCA indicators and LCIA methods than to develop new LCIA methods and quantify specific cause and effect chains, since (ii) it is beyond the scope and limitations of this paper. The selection criteria for such existing LCA indicators, LCIA methods, software environments, and databases are as follows: 


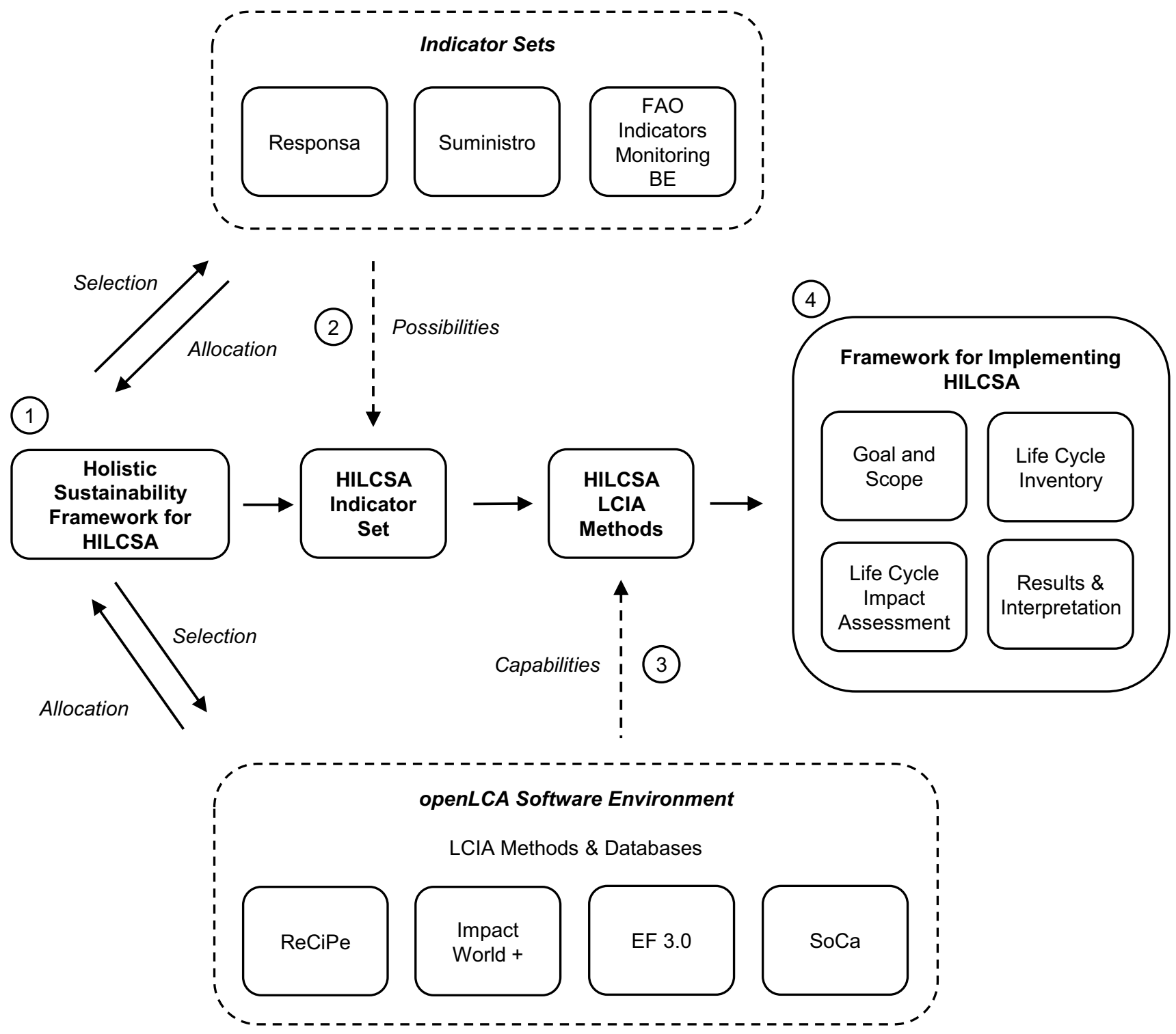

Fig. 1 Methodological steps for developing a framework for implementing holistic and integrated life cycle sustainability assessment (HILCSA) (LCIA life cycle inventory)

(a) Possibility of allocation to relevant SDG sub-goals and our HILCSA sustainability framework. (b) Capability of the given software environment to operationalize and implement them.

Table 1 Relational entities, aspects, background methodologies, and assigned SDGs of HILCSA (Zeug et al. 2020)

\begin{tabular}{llc}
\hline Relational entity, aspect, background methodology & Assigned SDGs \\
\hline HILCSA & Societal needs, social, S-LCA & $\begin{array}{c}\text { 1. No poverty, 2. zero hunger, 3. good health and well- } \\
\text { being, 4. Quality education, 5. gender equality, 11. } \\
\text { sustainable cities and communities }\end{array}$ \\
& $\begin{array}{l}\text { Provisioning System, economic LCA } \\
\text { energy, 8. decent work and economic growth, 9. }\end{array}$ \\
& $\begin{array}{l}\text { industry, innovation and infrastructure, 10. reduce } \\
\text { inequalities, 12. responsible consumption and produc- } \\
\text { tion, 16. peace, justice and strong institutions, 17. }\end{array}$ \\
& partnership for the goals \\
Planetary boundaries, ecological, E-LCA & 13. Climate action, 14. life below water, 15. life on land
\end{tabular}


(c) Maintain consistency and avoid redundancies in models.

(d) Relevance and applicability in regional bioeconomy.

(e) Transparency of methods and potential availability of data.

Thus, our methodology for developing a framework for implementation and operationalization of HILCSA is mainly guided by the relation between possibilities and capabilities of complex sustainability assessments.

\subsection{Possibilities of indicator sets}

Secondly, we select indicator sets from our previous research as well as a review of literature on indicators for bioeconomy assessment, and allocate them to the HILCSA sustainability framework (Fig. 1, (2)). From previous research, we take our attributional, retrospective RESPONSA S-LCA framework (Siebert et al. 2016, 2018a, b; Jarosch et al. 2020), and the SUMINISTRO framework designed to carry out an E-LCA combined with RESPONSA based on a multicriteria decision analysis approach (Hildebrandt et al. 2018b; Hildebrandt et al. 2019; Hildebrandt et al. 2018a; Hildebrandt et al. 2020). However, even though E-LCA and S-LCA results in SUMINISTRO were additively combined by MCDA, there is no designated (integrated) LCSA approach. We allocate the indicators from RESPONSA and SUMINISTRO to the SDGs on basis of preliminary work (Jarosch et al. 2020) with some adjustments, thereby criteria $\mathrm{a}$ and e are meet.

From the literature review, we consider the FAO indicators to monitor and evaluate sustainability of bioeconomy (Bracco et al. 2019) as the most comprehensive and recent indicator review basis available, in order to expand existing methods. For this reason, we did not conduct any additional review on indicator sets. In Bracco et al. (2019), indicators were categorized as (i) territorial, to measure the impact of bioeconomy at national, regional, or sub-national level (contribution of bioeconomy to overall sustainability on a macro scale) and (ii) product level indicators in product systems (to measure impact at a microscale when replacing fossil fuel resources with biological resources) (Bracco et al. 2019). We allocate all FAO indicators from product and territorial level to the HILCSA sustainability framework (criteria a). For this, we use the already-made assignment by the authors as well as an assignment of all remaining or questionably assigned indicators by their best descriptive capability of addressing an SDG sub-goal. If we cannot assign indicators to a specific sub-goal, we assign them to SDGs which they deliver information on, even if these aspects were not foreseen in the general SDG framework.
As a result of this second step, we gain an extensive indicator set which describes the possibilities of HILCSA (Fig. 1, (2)) (Table 2).

\subsection{Capabilities of software environments and LCIAs}

A given software environment is a precondition to manage the enormous complexity behind LCA methods and data in order to make them applicable in future case studies (Zeug et al. 2021) in line with our framework. In the course of this work, it becomes clear that due to strong interdependencies, the development of a framework cannot be carried out independently of a specific software. In the third step (Fig. 1, (3)), we choose openLCA as the only software environment capable of incorporating social, ecological, and economic aspects in LCA as well as different functional units and activity variables (Di Noi and Ciroth 2018; Di Noi et al. 2018; Eisfeldt et al. 2017). In openLCA are S-LCA functionalities as well as SoCa and PSILCA as socioeconomic databases implemented and constantly further developed (criteria e). For social indicators, data, and LCIA, the only software implementation available is SoCa. Based on Ecoinvent, simultaneously making Ecoinvent the process database most suitable in this context to avoid incompatibilities (Eisfeldt et al. 2017; Di Noi and Ciroth 2018). Additionally, only openLCA aims explicitly at an implementation of integrated LCSA (Di Noi and Ciroth 2018; Di Noi et al. 2018). Even though there is no LCSA functionality in openLCA or application yet, openLCA was considered for this work as the most promising platform, also regarding a broad set of implemented LCIA methods (criteria b). Especially for environmental impacts, there are a variety of more or less well-established LCIA methods. To compile LCIAs for our indicator set and to define the capabilities, we select LCIA methods from literature and openLCA method database, which are able to address most SDG sub-goals at their midpoint or endpoint level, so we can allocate them to our framework (criteria a): open LCA-SoCa (Eisfeldt et al. 2017), openLCA-ReCiPe 2016 (H-Hierachrist) (Huijbregts et al. 2017), Impact World +(Bulle et al. 2019) and Environmental Footprint 3.0 (Fazio et al. 2018), and CEDCumulated Energy Demand from openLCA (Table 2).

To finally gain an implemented and operationalized HILCSA framework in step four (Fig. 1, (4)), meeting all the defined criteria, we check for redundancies in the indicator set and LCIAs as well as maintain as much consistency as possible from each of the individual methods (criteria c). In a last step, we sort out all indicators which are not applicable and relevant in regional bioeconomy assessments (criteria d). For this, we use the relevances of corresponding SDGs and sub-goals, which we gained by stakeholder participation (Zeug et al. 2019), and keep all indicators whose SDGs must and may be part of bioeconomy monitoring. Not every 


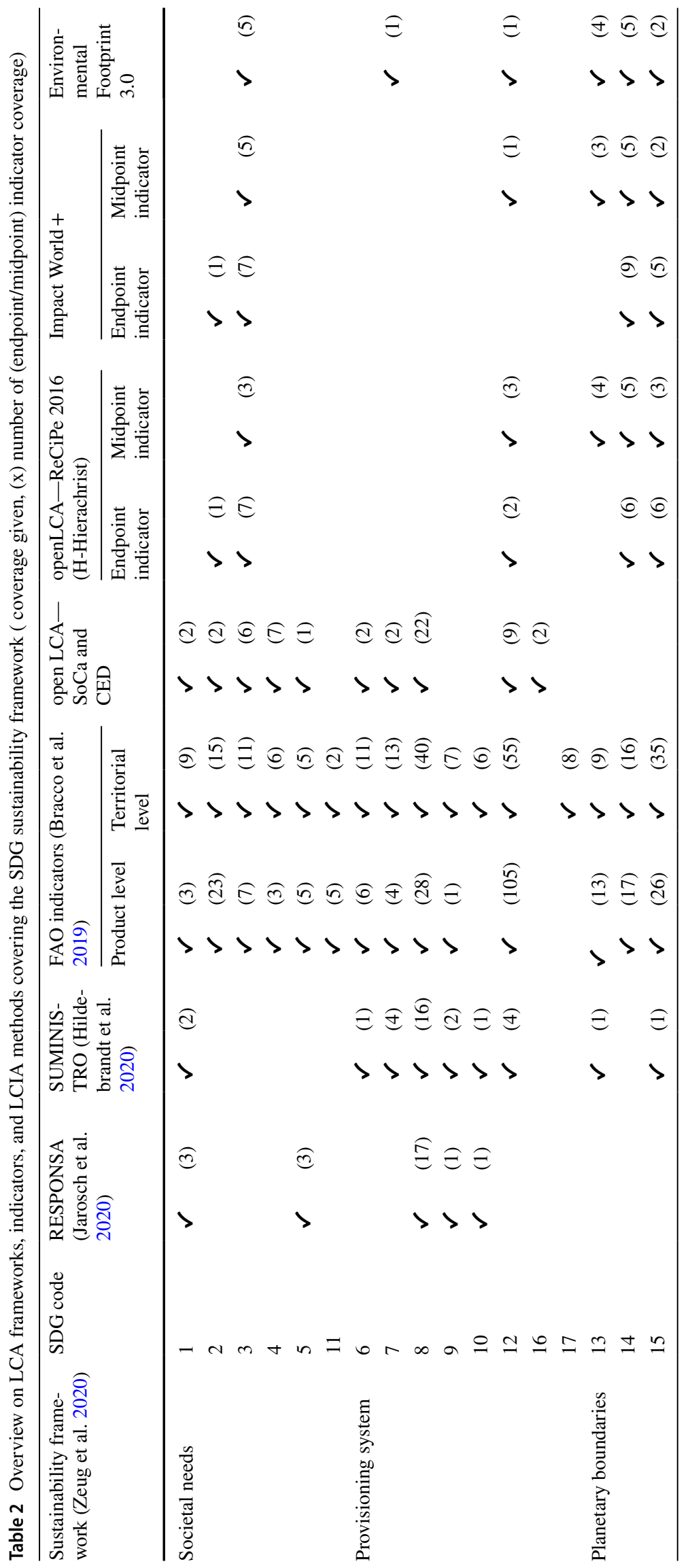


SDG indicator of global relevance necessarily plays a role in regional bioeconomy assessments, even when external or international effects are considered diligently. Still, LCAs and their indicators have to consider international effects, since first, using local or global indicators depends on the nature of environmental pressures and its causes (globalGHG, local-acidification), and second, a spatial dissociation between places of extraction, production, and consumption distributes social and economic effects globally (Parrique 2019). We furthermore test these tools and develop and apply methods of normalization, weighting, and aggregation to gain a consistent methodology. As a result, a comprehensive LCI and LCIA is set up (Table 4). Such a practical framework for HILCSA within limited capacities is only possible if it builds on existing and appropriate methods and research that to most extent meet the methodological criteria for HILCSA. Consequently, not every assumption of these approaches goes in line with our framework; some technical detail can only be discussed and regarded to a limited extend, and compromises have to be made.

\section{Framework for implementation and operationalization of HILCSA}

Previously, we discussed a sustainability framework for HILCSA, in contrast to the widely used three-pillar approach (Zeug et al. 2020). We define social sustainability as the long-term and global fulfillment of societal needs and social well-being as an end; ecological sustainability is the longterm stability of our environment as a basis of reproduction within planetary boundaries; economic sustainability stands for technologies and economic structures which are efficient, effective, and just provisioning systems relating societal needs and environment (Fig. 2, i). Basic for implementation and operationalization of this sustainability framework and HILCSA is the integrated approach, inspired by Guinee et al. (2011): HILCSA = $\mathrm{f}($ S-LCA, E-LCA, LCC) as a holistic integration of social, economic, and ecological aspects in a common goal and scope, LCI, LCIA, results, and interpretation (Fig. 2, ii). Integration in this sense means.

- Horizontal holistic integration: integrating different aspects and categories of impacts (social, ecological, economic).

- Vertical integration: integrating scales and scopes (product and territorial into regional level) (Zeug et al. 2020; Sala et al. 2012b).

In the following, we present this framework (Fig. 2, ii), step by step structured likewise to ISO14040— goal and scope, LCI, LCIA, and interpretation.

\subsection{Goal and scope}

Goal of the HILCSA methodology and its future case studies is the assessment of social, environmental, and economic impacts as risks and chances of regional bioeconomy product systems, their contributions to the SDGs, and a socio-ecological transformation. In specific, this means to quantify and qualify social, environmental, and economic performance of bioeconomy product systems, to identify main hotspots, and when possible to compare this performance and hotspots with fossil product systems to understand the contribution of bioeconomy product systems to regional and global holistic sustainability. i)

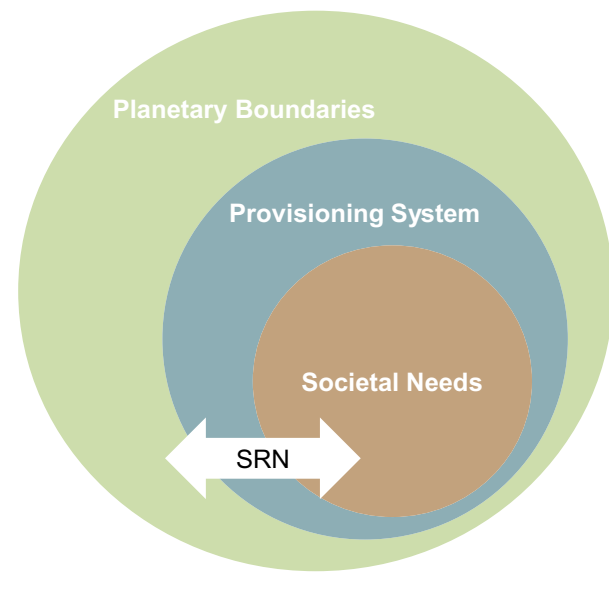

ii)

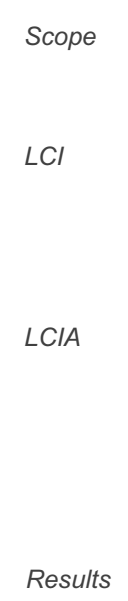

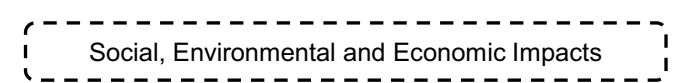

Functional Units -

Activity Variable
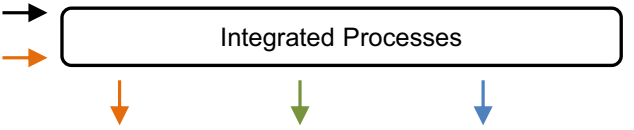

Indicators

Societal Needs | Provisioning System | Planetary Boundaries$$
\text { renticators }
$$

Relative \& Absolute Assessments

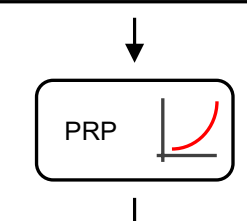

Weighted Indices of Relative and Absolute Performance

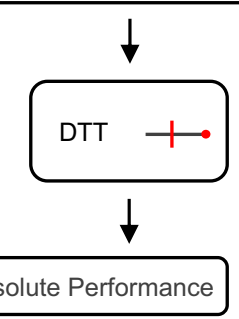

Interpretation
Fig. 2 (i) The integrated model of holistic sustainability in LCSA based on the Societal Relations to Nature and (ii) holistic and integrative scheme of HILCSA $=f(S-L C A, E-L C A, L C C)$ based on (i) (SRN Societal Relations to Nature, PRP relative method of impact assessment by performance reference points, DTT absolute method of impact assessment by distance to target, LCI life cycle inventory, LCIA life cycle inventory) cf. (Zeug et al. 2020) 
Because wood has the greatest economic importance and most versatile use among renewable resources, the specific scope of our methodology and future case studies (Zeug et al. 2021) are regional wood-based bioeconomy product systems of Central Germany as a foreground system and, respectively, international/multi-regional interlinkages as background systems (UNEP 2020). Wood is not produced and used exclusively regional (Weimar 2015; Budzinski et al. 2017). Forests can provide increasing but limited resources for renewable materials, e.g., construction materials as laminated veneer lumber (LVL), and have a significant potential to mitigate climate change due to their capability of sequestering and storing carbon (Sahoo et al. 2019). LVL is an engineered wood product that uses multiple layers of more or less thin wood sheets assembled with adhesives like phenolic resin and manufactured as beams; it can substitute fossil-based construction materials like steel or steel concrete beams. However, when sustainable forest management is applied, a fully substitution of the existing material demand is unlikely, making absolute decreasing, optimal, and circular and/or cascading production and use even more critical (Sahoo et al. 2019; EU 2015). In general, due to the oftentimes decentral occurrence and cultivation of biomass, associated activities and their barriers are also of a regional and decentral character. The climate, soils, and cultivation practices can vary regionally and thus significantly determine biomass production, its regional distribution, and ecological barriers (O'Keeffe et al. 2016).

As usual, we model products and their life cycles as a product system (Fig. 3), reduced to its essential functions, characterized by material flows, and differentiated from the system environment by system boundaries. The product system contains all essential processes associated with the product and interactions with other systems. For describing its regional and global effects, the life cycle must be broken down into its essential process steps and unit processes. Generally, for wood-based products like LVL, the resource and first process step is roundwood-as well as residues from harvesting and processing (e.g., branches and bark) can be used for bioenergy and innovative biomaterials from cellulose (Sahoo et al. 2019)—feeding subsequent processing and conversion industries. Long and broad value-added networks can result from a cascade of utilization, recycling, and integrated bio-refineries entailing thermochemical, biochemical, and physicochemical conversion processes with a possible integration of by-products (Smetana et al. 2016). A simplified, model-based product system which is modularly designed is common in LCAs. Process steps are simplified as linear and chronologically occurring aggregates of unit processes. So, each step consists of at least one unit process as the smallest balancing unit, defined by the characteristic physical intermediate material flows and their qualitative change. In regional LCSA, these unit processes rarely describe specific technical processes, but mostly entire companies and production sites.

The geographical system boundaries are derived from economic boundaries, i.e., the main level of impacts can be regional, national, or global. In this regard, a geographic region is defined as a bioeconomy region when predominant economic activities of biobased production systems are concentrated and the majority of required primary raw materials

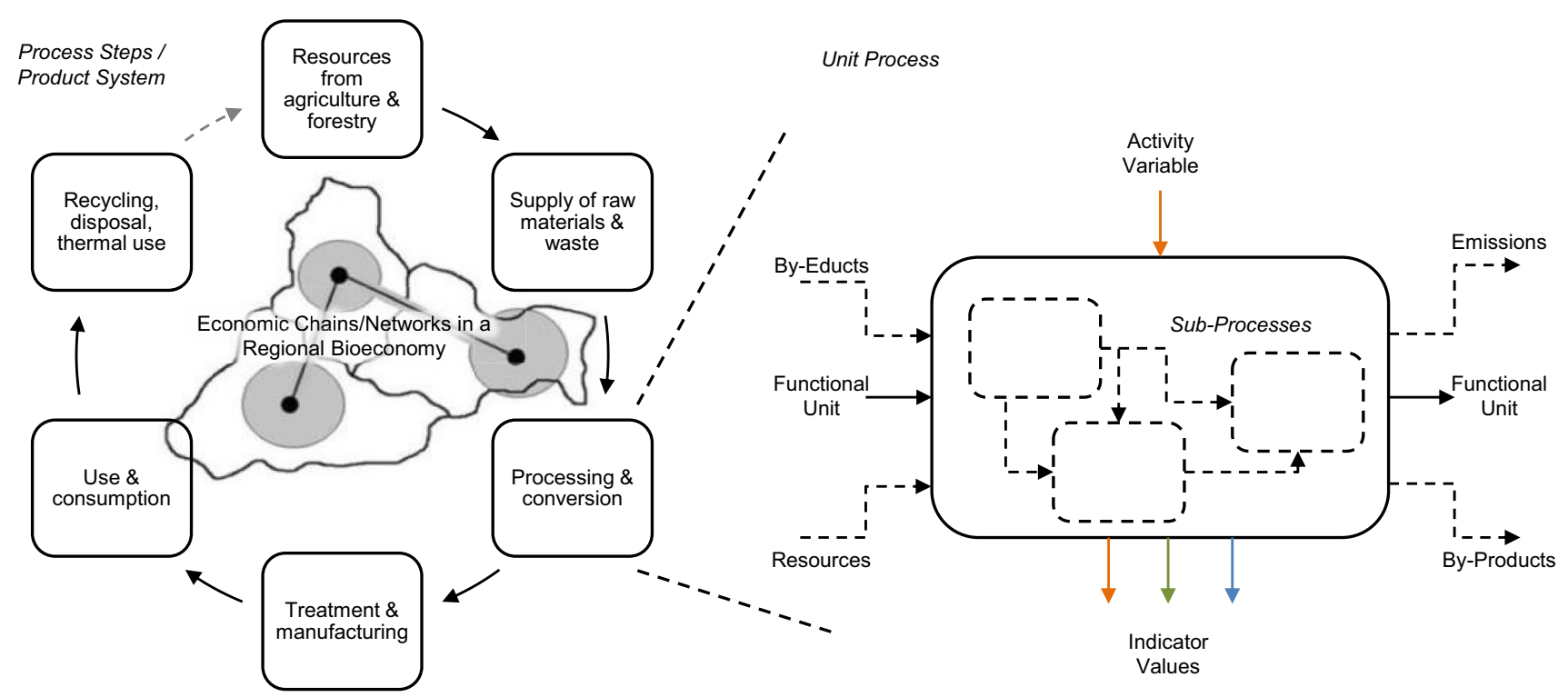

Fig. 3 Product system as process steps and unit processes in holistic and integrated life cycle sustainability assessment (HILCSA) of regional Bioeconomy 
are obtained there, as well as social, economic, or ecological correlations with environment or society are significant in this very region (Siebert et al. 2016, 2018b). Because of the sustainability potential and most social impacts within the production sphere, as well as due to data availability, most LCA studies are conducted as cradle to gate (Suwelack 2016). Prospectively, this needs to be overcome in regard to circular economy as a basic principle of sustainable bioeconomy (use and recycling/disposal). Whereby the distribution sphere has not always to be considered, due to its comparatively low effect (despite of transport). As a general criterion, it is important to take all significant interactions with environment and society into account, as well as to make all neglected aspects transparent by cutoff criteria to be set.

Regarding the general character of the assessment, there is an ongoing debate on whether to assess sustainability in absolute or relative manner, and latest publications on E-LCA argue increasingly strong for an absolute environmental sustainability assessment (Bjørn et al. 2020; Castellani et al. 2016; Robert et al. 2020; Sala and Castellani 2019; Sala et al. 2020). Every relative assessment needs to have a reference on which the results depend in a qualitative and quantitative way, e.g., if the case to be observed is better than a reference of cases and how much it is. For example, within the common E-LCA of SUMINISTRO, an optimal product composition and an optimized feedstock mix for beach fiber laminate boards and LVL were identified to assess the potential mitigation of environmental impact when producing $1 \mathrm{~m} 2$ of such product. Such hotspot analyses meet the basic requirements of product system improvement. However, there is no or very limited information, if it performs "well enough" to be part of an environmentally sustainable economy, e.g., what the space for improvement is or has to be (Bjørn et al. 2020). Whereas absolute sustainability assessment methods (Chandrakumar and McLaren 2018b) compare specific impacts with external environmental carrying capacities (according to planetary boundaries) as impact pathways LCIAs (UNEP 2020), e.g., life cycle climate impacts are related to the $1.5^{\circ}$ climate goal (Bjørn et al. 2020). However, introducing new parameters such as downscaled planetary boundary and complex causeeffect chains comes with a higher uncertainty due to limited knowledge at the current stage of research. Besides, for social (societal needs and social well-being as an end) and economic aspects (efficient, effective, and just provisioning systems), there are no defined quantitative boundaries, rather there are qualitative development pathways which are quite context specific (Jarosch et al. 2020; Siebert et al. 2018b; Hauschild et al. 2008; Zamagni et al. 2011). The social effects in RESPONSA are directly related to a specific intermediate product with means of an individually developed and context-specific set of indicators and data of federal statistical agencies. For such aspects, a relative sustainability assessment as reference scale LCIA (UNEP 2020) by calculating performance reference points (PRPs) on the basis of a distribution of reference value is applicable, and also the most common method in S-LCA (Jarosch et al. 2020; Siebert et al. 2018b).

\subsection{Life cycle inventory}

The operational core of HILCSA is integrated processes of regional bioeconomy product systems in the openLCA software environment. The process units are designed following the integrated LCSA approach (cf. Keller et al. 2015) and the openLCA implementation with SoCa. Such an LCI of HILCSA has to integrate a number of indicators of different character, on which we focus first.

\subsubsection{Indicator system}

From the studies and methods we consider, we identify in total 708 possible indicators for bioeconomy assessment on territorial and product level. The FAO indicator report (Bracco et al. 2019) provides the best overview of possible indicators, 248 on product level and 252 on territorial level, and is a helpful reference for setting up possibilities of an indicator system. While it does not provide directly applicable indicators or methods for HILCSA, taking it as a reference template and allocating LCIAs to it already produces a bioeconomy-specific indicator system. Thereof 566 nonredundant (criteria c) indicators can possibly be applied to regional bioeconomy assessments by allocating them to SDGs and our HILCSA sustainability framework (criteria a). These indicators describe 118 social, 130 ecological, and 318 economic aspects assigned to 74 SDGs and sub-goals (Table 2). For 95 SDG sub-goals, there are no indicators yet, mainly SDG 16, 17, 10, and 3. Especially for SDG 16, there are no direct indicator links in the current literature, and it is more a cross-cutting issue for bioeconomy (Calicioglu and Bogdanski 2021).

In the following, we keep all indicators whose relevance of corresponding SDGs is significant for bioeconomy monitoring (criteria d, "must and may be part of monitoring" (Zeug et al. 2019)), and which are available within LCIA methods and databases of openLCA (criteria $b$ and e). Some of the SDG sub-goals and indicators which are not applicable in a LCSA of bioeconomy are excluded from the LCI (criteria b), e.g., policy coherence in sustainable development (SDG 17.14). As a result, we consider HILCSA capable of 109 indicators (Table 3). RESPONSA contributes 12 practically applicable indicators for the provisioning system and 4 indicators for societal needs (mostly addressing working conditions). Some RESPONSA indicators are left out since there is a redundancy and to high level of detail (Jarosch et al. 2020) 


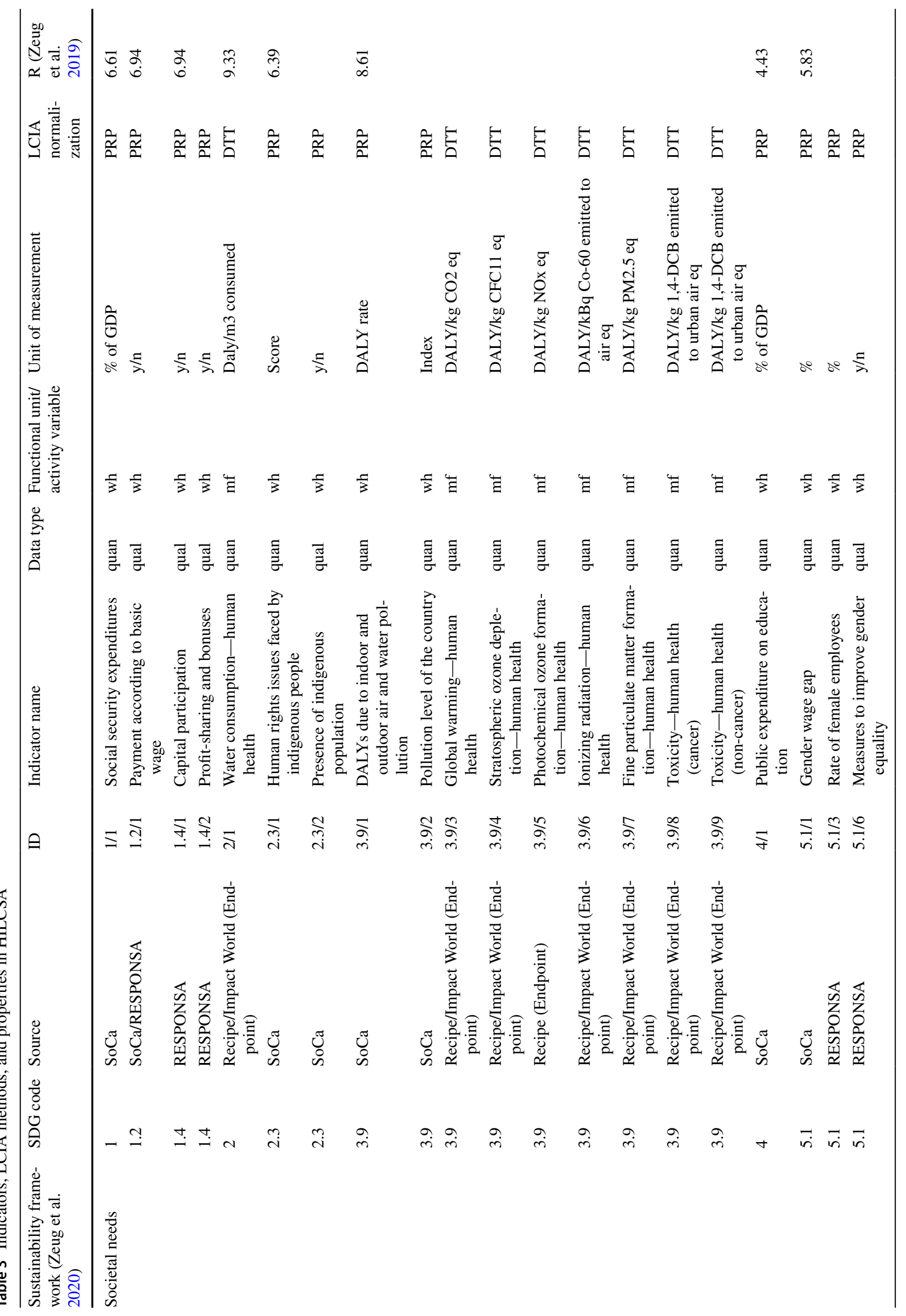




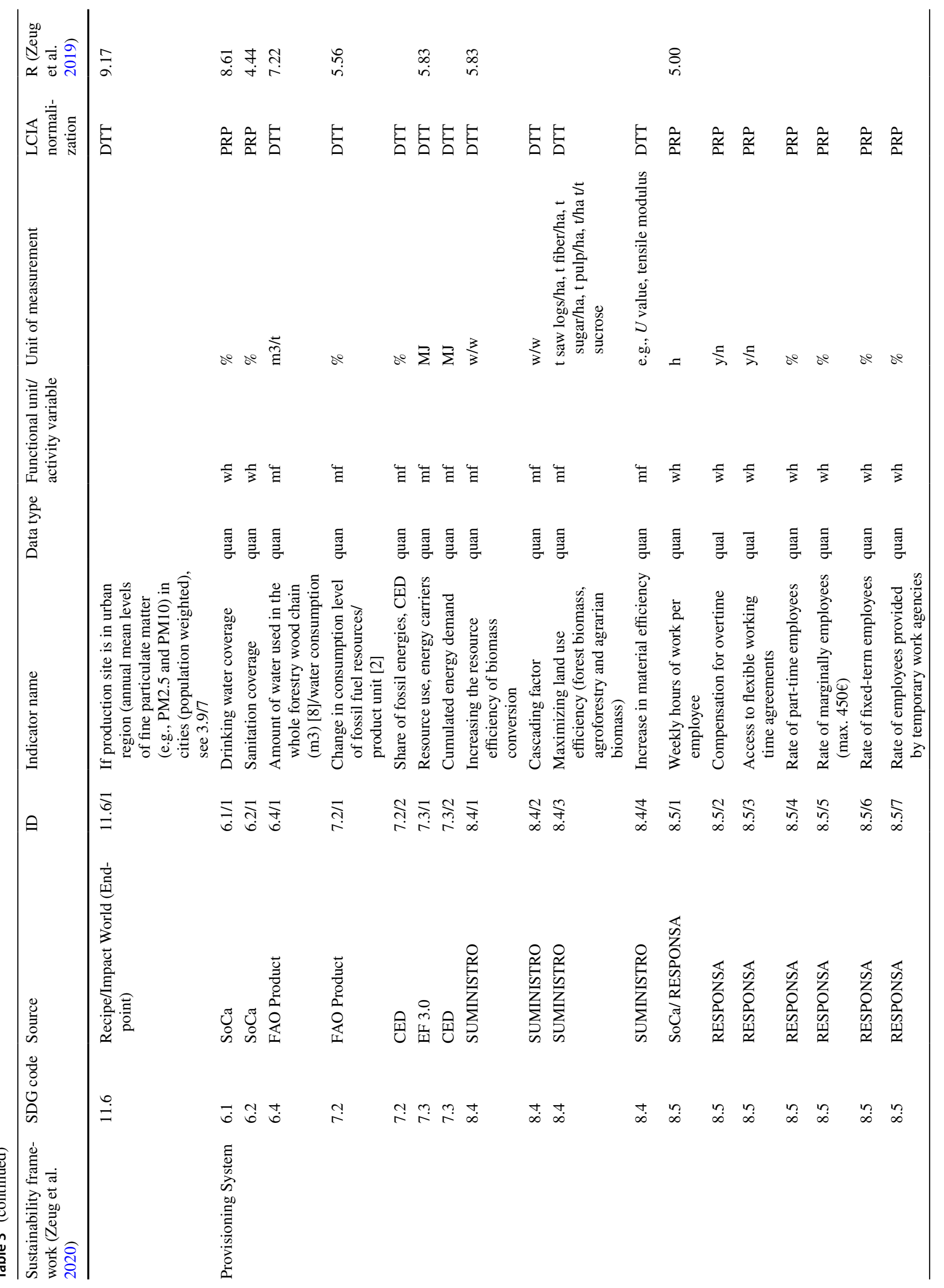




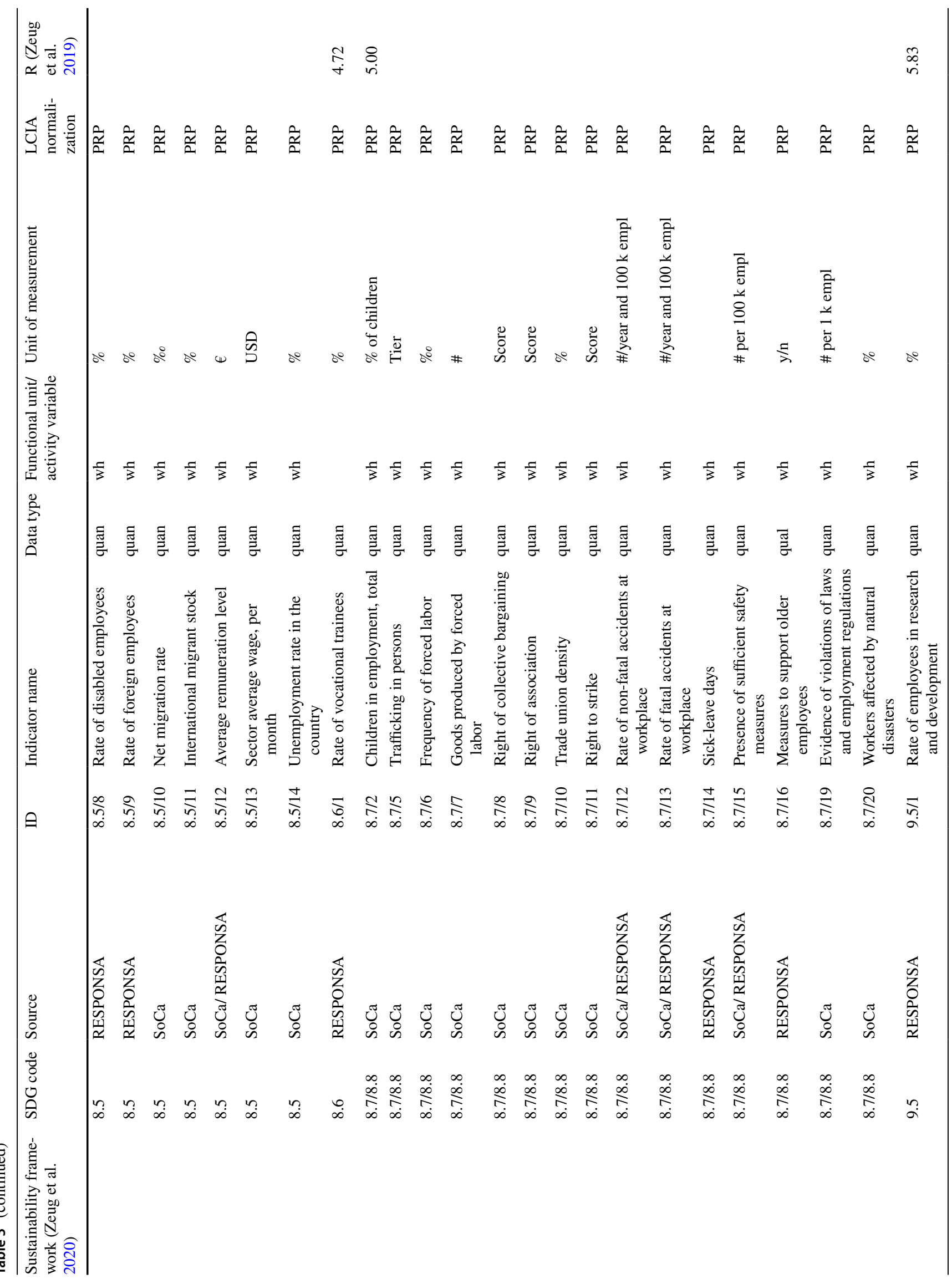




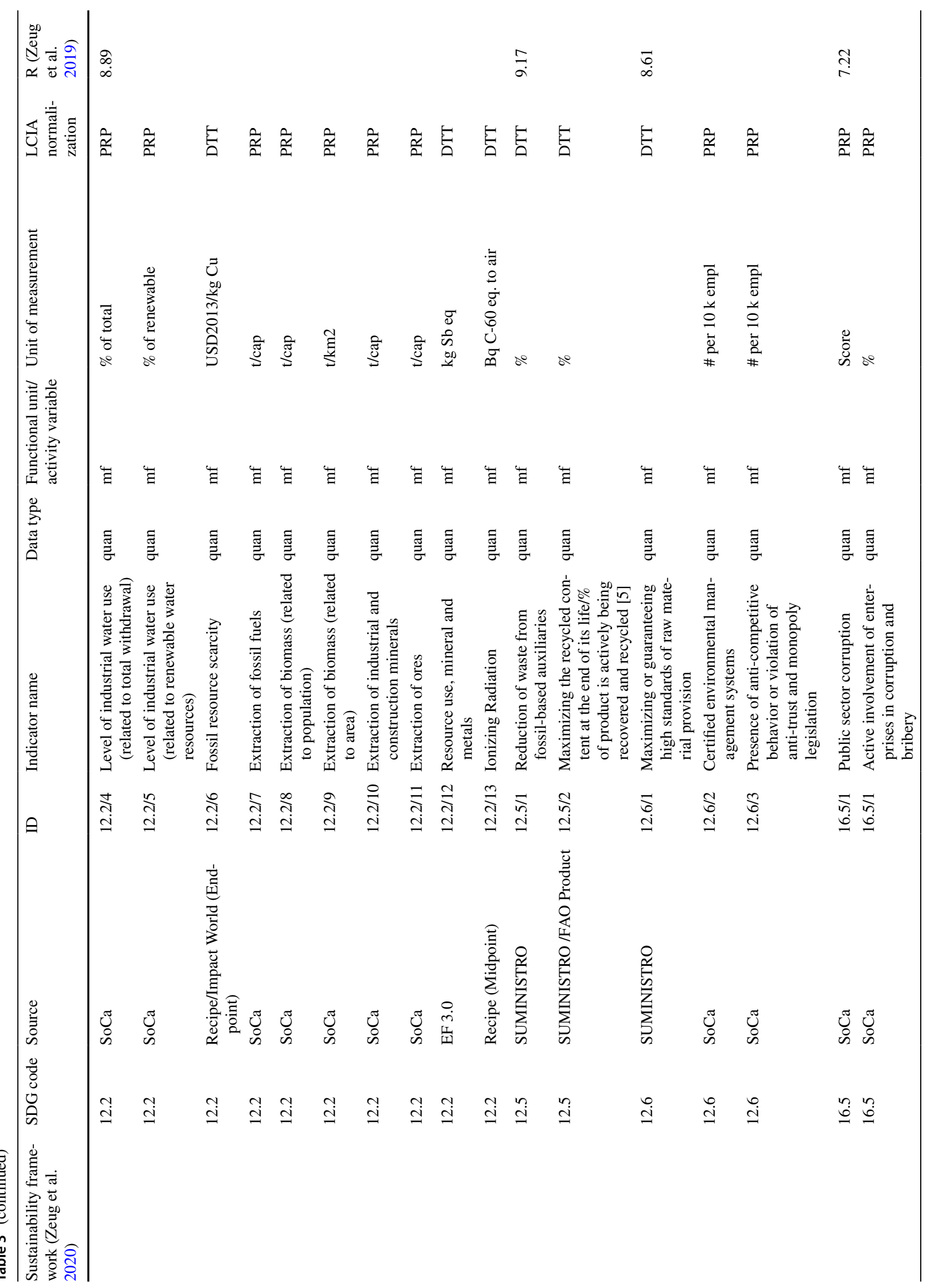




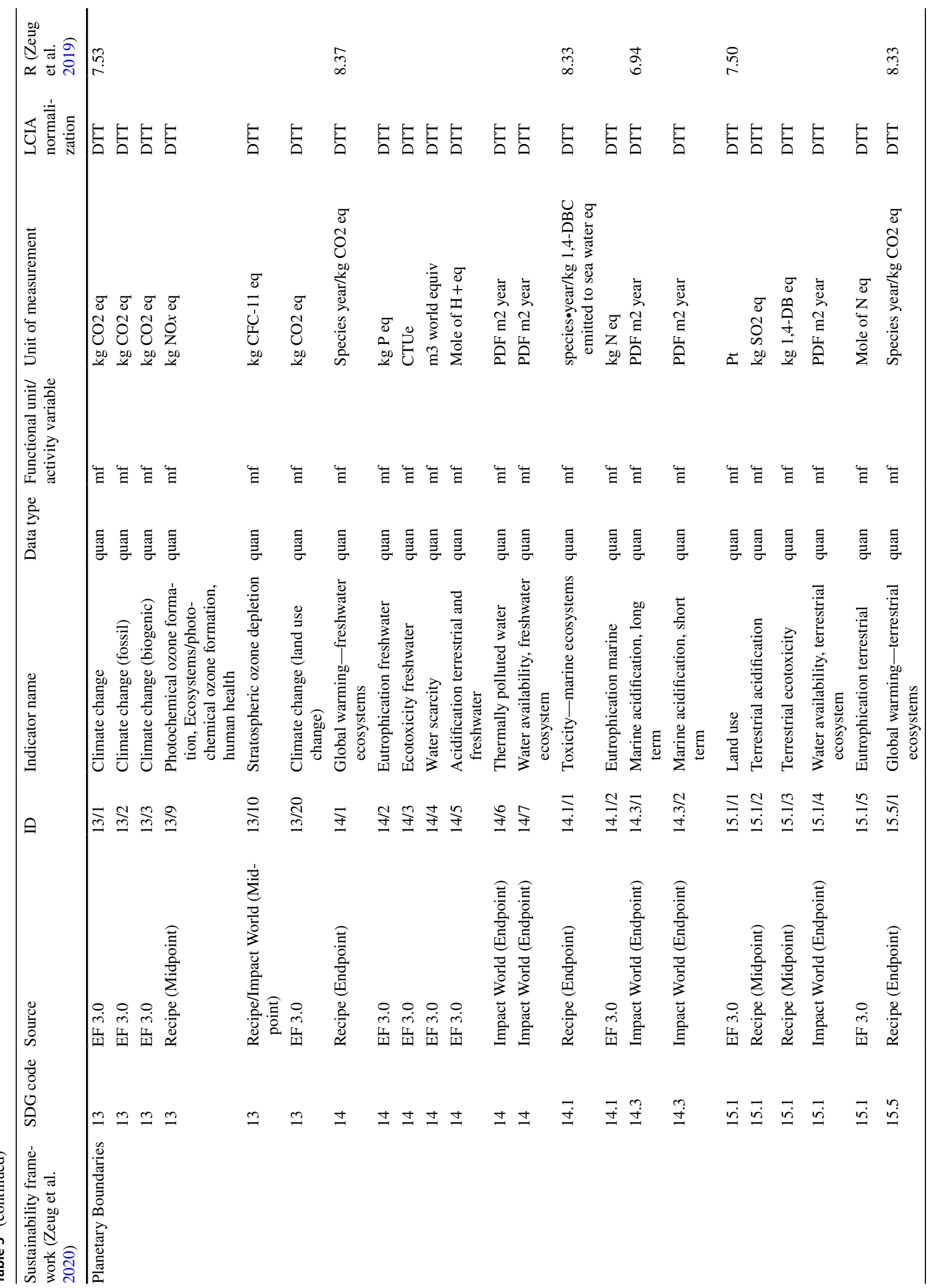


or SoCa covers them. When indicators are already available within an established LCIA method, we prefer them because of their better practicability and robustness. The same is true for SUMINISTRO, delivering valuable data for later case studies (Hildebrandt et al. 2020; Siebert et al. 2018b) and 7 indicators mainly including technological process characteristics (e.g., efficiencies, cascading factor). All other (midpoint/endpoint) indicators come with the LCIA methods available in openLCA (Acero et al. 2016) and chosen for HILCSA: SoCa, ReCiPe 2016 (H), Impact World +, and EF 3.0.

As a typical consequence in LCSA, this framework is not as detailed as in stand-alone methods (Taylor et al. 2017). Rather, the goal is to avoid a piecemeal approach to sustainable transformation and the capability of delivering a holistic picture on trade-offs, synergies, hotspots, significant risks, and chances as well as a fundamental understanding (Zeug et al. 2020). In addition, more indicators do not necessarily lead to a better quality necessarily, but an adequate impact category coverage is of particular importance (Lindqvist et al. 2019). The 109 possbile indicators are already quite much compared to most other studies and potential data availability.

In Table 3, we allocate all indicators to our sustainability framework (societal needs, provisioning system, planetary boundaries) (Zeug et al. 2020), the SDG subgoals (or SDGs) by the official SDG codes (UN 2015), and gave them a HILCSA-specific ID composed of the SDG code and the sequential number of indicators of this SDG. Indicators have a qualitative (categorical, limited number of values) or quantitative (continuous, unlimited number of values) type of data. Qualitative indicators mostly occur when specific measures (yes/ no) in societal needs and the provisioning system are evaluated. We also categorize all indicators by having a physical functional unit (material flow) or an activity variable (working hours) (see Sect. 3.2.2), and their unit of measurement which is the same as from the source of the indicator. As mentioned, the indicators of HILCSA have an absolute (impact pathway) or relative (reference scale) character important for their LCIA (see Sect. 3.3). The relevance of the indicator is derived from the respective relevance of its SDG and sub-goals according to our stakeholder participation process, and shown as a decimal score ranging from 4.43 to 9.33 (Zeug et al. 2019, 2020).

Since all indicators in the LCI are not modified and are integrated in HILCSA as they were presented in their original studies, we will not discuss any indicators individually here, but refer to the relevant literature. 


\subsubsection{Functional units and activity variables}

Only one functional unit or reference material flow is not sufficient for accounting impacts on social, economic, and ecological systems. Rather, additional activity variables need to be used (Costa et al. 2019; Urban et al. 2018; Zamagni et al. 2013). The activity variable for balancing social and some economic impacts has similarities with elementary flows, and is used to represent the impact share of a process step or unit process (UNEP 2020). The crucial difference is that most social as well economic effects of the production of a commodity are not directly related to the amount of physical output of a process, but are mediated through complex socioeconomic relations (Zeug et al. 2020; Dreyer et al. 2006; Benoit et al. 2006). From those can be derived that socioeconomic effects are balanced by the number of working hours required to produce the functional unit (UNEP 2020; Zeug et al. 2020; Siebert et al. 2018b). Nevertheless, working hours are quite indirectly related to some social indicators, e.g., drinking water coverage or displacements of local communities, for which new approaches are under development (Ciroth et al. 2019; UNEP 2020).

In case of material use of wood products generally, a unit, volume, or mass of products (material flow) is used as functional unit (Sahoo et al. 2019), e.g., the production of 1-m3 LVL. When several conversions take place or a complex regional bioeconomy product system is assessed, it is difficult to break everything down to one final product as functional unit, since calculations can easily get unpractical (e.g., properties of wood products and educts such as variable water content result in variable mass and volume as well as a variety of different end-products). Therefore, the resource-related mass of wood fiber equivalent (WFE) of the end products should be considered (Weimar 2015; Budzinski et al. 2017), excluding water and additives and confining the functional unit to the actual mass fraction of lingo celluloses in each process step and unit process.

For our purposes, openLCA with SoCa as software environment for implementation of HILCSA sufficiently supports a variety of functional units (mass, volume, product units, WFE) as well as working hours as activity variable.

\subsection{Life cycle impact assessment}

Like in LCA and S-LCA, the LCIA aims at calculating, understanding, and evaluating the magnitude and significance of actual or potential impacts of a product system throughout the life cycle (UNEP 2020). Within the LCIA, we link indicators by classification, normalization, weighting, and aggregation to the sustainability framework and the SDGs as well as sub-goals as end point impact categories. From 109 indicators, we assign 20 to societal needs, 60 to the provisioning system, and 29 to planetary boundaries-thereby covering 30 SDGs and sub-goals (Table 3). Only SDG 17 and 10 cannot be addressed at all. The SDG sub-goals 8.7 (worker rights, abolition of forced labor/trafficking/child labor) and 8.8 (worker rights, labor protection rights, promoting safe work environment) were merged, since they differ not significantly in terms of impact categories and a better aggregation and weighting is possible.

As part of the LCIA, in RESPONSA and partly SUMINISTRO, the performance of organizations of the life cycle was compared with a statistical reference and resulting dimensionless PRPs (Siebert et al. 2018b) give an indication on the social performance of a product life cycle (e.g., LVL) (Jarosch et al. 2020; Hildebrandt et al. 2020). For most of the planetary boundaries-indicators and some indicators of societal needs, whose effects have their cause in physical emissions, we follow impact pathway LCIA approaches to assess consequential social impacts through characterizing the cause-effect chain (cf. (UNEP 2020)).

There are a series of heterogeneous and mostly incompatible environmental LCIA methods for the environmental assessment of bioeconomy value-added chains (Cristóbal et al. 2016), but we follow the recommendation of the EC-JRC by using the LCA-based Product Environmental Footprint (PEF) methods (Fazio et al. 2018) (EC and JRC 2010). Environmental Footprint can be seen as the most robust and comparable environmental accounting concept (Manfredi et al. 2015). Environmental Footprint and PEF are most suitable in HILCSA because of two main reasons: They provide a best practice to include global effects into a meso-level assessment such as LCSA, and thereby bridge the gap to global and national goal systems like the SDGs (Wulf et al. 2018) as well as planetary boundaries. The growing importance of planetary boundaries and the finite nature of the environment led to absolute sustainability assessment methods in LCA, recently (Bjørn et al. 2020; Sala et al. 2020). Absolute sustainability assessment methods evaluate if an industrial metabolism on different scales (ranging from products, regions to whole economies) is (un-)sustainable in an absolute sense of regional and global boundaries for a comprehensive set of impact categories (Bjørn et al. 2020). However, there are planetary boundaries, SDGs, and sub-goals not covered by Environmental Footprint (e.g., ozone formation/ depletion, loss of biodiversity, terrestrial acidification/ toxicity) (Chandrakumar and McLaren 2018b) for which we chose midpoint and endpoint indicators from ReCiPe 2016 (H-Hierachrist) (Huijbregts et al. 2017; Huijbregts 2016) and Impact World + (Bulle et al. 2019). In ReCiPe 2016, the hierarchist perspective is chosen, since it represents the scientific consensus with regard to timeframe and plausibility of impact mechanisms (Huijbregts 
2016). For some midpoint indicators which are highly regional specific (e.g., water availability), the Impact World + LCIA is more appropriate, because of country default, and native resolutions (Bulle et al. 2019). However, Impact World + is still to be implemented in openLCA in near future.

Combining several LCIA methods within one framework is necessary to cover all impact categories and not per se problematic (Wulf et al. 2017; Di Noi and Ciroth 2018). Though, a consistent implementation of several LCIA requires a careful analysis of their units, impact factors, and normalization methodologies (e.g., SoCa uses risk levels and specific impact factors which have to be applied to the PRPs and are not comparable and cannot be aggregated with plain results of ReCiPe or Environmental Footprint) as well as to avoid double counting one impact in several LCIAs and impact categories. Nevertheless, in the following case studies (Zeug et al. 2021), a sensitivity analysis is required to cross-check for impact shifting. We do not change the different LCIA methods or characterization factors in order to keep consistency (criteria c). For all other indicators, we do not conduct any impact pathway characterization, but follow directly a reference-scale assessment approach (see Sect. 3.3.1) (UNEP 2020).

Even more important and controversial in LCSA than in LCA are the optional steps of normalization, weighting, and aggregation of impact categories, due to increased complexity of results and how to communicate them to different stakeholders (Wulf et al. 2017; Andreas et al. 2020). At this early stage of overall method development, in future case studies, we will present plain results as well as normalized, weighted, and aggregated results (Valdivia et al. 2012; Wulf et al. 2017).

\subsubsection{Normalization}

In order to compare different indicators and impact categories with different units with each other, various forms of normalization in LCIA can be performed at midpoint and endpoint levels (Andreas et al. 2020). This is a prerequisite for aggregation as well (Wulf et al. 2017). In general, normalization can be done by internal reference (maximum/ minimum values or ratios from within the LCI) or external reference (external data of systems and rankings) (Prado et al. 2012; Wulf et al. 2017). Provided that internal normalization comes with several fundamental methodological issues, we prefer recommended external normalization (ibid.). However, external normalization factors can increase uncertainty of the whole assessment (Wulf et al. 2017), and the choice of reference values plays a vital role (Sala et al. 2012a).

Normalization in HILCSA requires to incoporate two types of LCIAs (Fig. 4): (i) the relative performance of a particular bioeconomy system in relation to a reference system and (ii) the absolute benchmarking of a particular bioeconomy system against planetary boundaries. Therefore, available methods of impact assessment are the following: (i) PRPs as reference scale approach and (ii) distance to target (DTT) as impact pathway approach. On the one hand, measurements of relative performance can compare provisioning systems like bioeconomy at their status quo and do not rely on global models, quantitative goals, or thresholds. This is especially true for impact categories of societal needs and provisioning systems to which (i) relative PRPs are mostly applied. They have accompanied S-LCA methods for a long time in various forms (Traverso et al. 2012; Siebert et al. 2018b). On the other hand, absolute

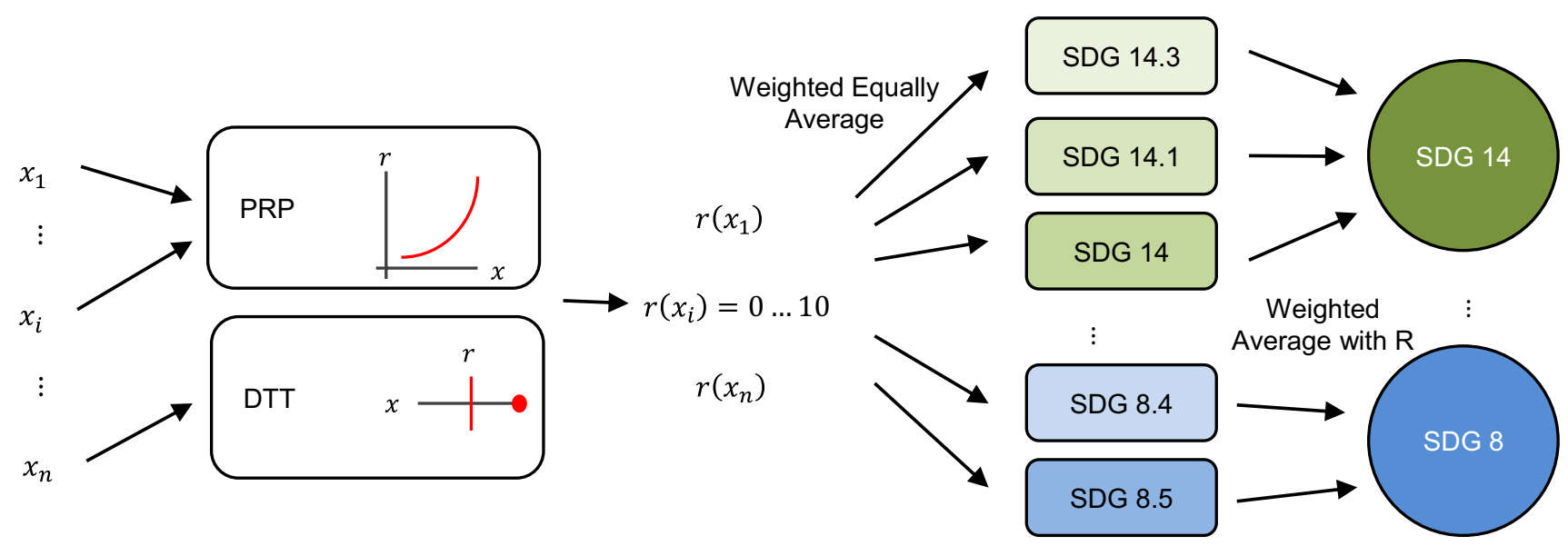

Fig. 4 Scheme of indicator normalization, weighting and aggregation (SDG sustainable development goals, PRP relative method of impact assessment by performance reference points, DTT absolute method of impact assessment by distance to target) 
sustainability assessment methods are concerned with the potential transgression of regional and global boundaries (Bjørn et al. 2020). Only absolute measurements can provide information on whether the status quo of even one of these provisioning systems is sufficiently sustainable at all, and if not, how much. Therefore, the impact category planetary boundaries are normalized by (ii) absolute DTT. In the end, integrated LCSAs entail many different indicators, measurements, and units. Thus, dimensionless scores are necessary and practical to allow comprehensibility. We carry out evaluations by calculations, which use distributions, threshold values, benchmarks, or ideals as measurement scales and output result for PRP and DTT in a dimensionless score $r$ ranging from $r_{\min }=0$ to $r_{\max }=10$ (Siebert et al. 2016). The score $r_{\min }$ represents the worst performance and $r_{\max }$ the best performance (Siebert et al. 2018b). This approach in general can be applied on a global, national, sectoral, regional, and product-specific level.

3.3.1.1 Performance reference points The normalization method of PRPs for quantitative and qualitative indicators was extensively discussed in our previous studies (Siebert et al. 2016, 2018b, a; Jarosch et al. 2020; Hildebrandt et al. 2020): The reference, against which assessment takes place, is not a singular value, but a spectrum of values we interpret as a distribution of an indicator $i$. The databases of the SDGs as well as Ecoinvent for ecological and the IAB as well as the Federal Statistical Office for social and economic indicators are sources of these reference data. Especially reference data of context-specific relative indicators have to be differentiated by region and sector of activity in a regional bioeconomy (Siebert et al. 2018b). The valuation, based on the assignment of scores to indicator expressions, is actually an ordinal scale, but treated as a cardinal scale for aggregation calculations (UNEP 2020). For detailed information on PRP methodology, see Appendix 1. Similar to PRP, the SoCa LCIA and its implementation in openLCA apply different scores for qualitative and quantitative indicators which in the end are assigned to risk levels (very low risk; low risk; medium risk; high risk; very high risk) (Eisfeldt 2017). In future case studies, we will combine these two approaches by assigning risk levels to PRPs and vice versa (Zeug et al. 2021).

3.3.1.2 Distance to target The planetary boundaries describe carrying capacities as instrumental values of natural resources and ecosystem services, e.g., in case of bioeconomy as renewable resource use: the maximum persistent impacts environments can sustain, without suffering perceived unacceptable impairment of their functional integrity (Bjørn et al. 2020; Bjørn and Hauschild 2015). These carrying capacities are mostly a combination of policy targets and biophysical (science-based) thresholds (Chandrakumar and McLaren 2018b; Sala et al. 2020).
However, LCIA results cannot be compared directly against planetary boundaries (Sala et al. 2020), but they can be downscaled to a specific region, and under certain circumstances to a regional provisioning systems, when a share based on one or more normative sharing principles (e.g., equal per capita) is assigned to them (Ryberg et al. 2020; Bjørn et al. 2020; O'Neill et al. 2018). In principle and analogously to PRP, these targets values can serve as normative best practice in reference and therefor rated with $r_{\max }$ if not transgressed. Although there are huge efforts on EU level towards this promising approach (Sala et al. 2020), currently in context of this very study, it seems not feasible to the authors to operationalize an absolute sustainability assessment methods for planetary boundaries allowing to calculate a product specific environmental threshold, e.g., how much $\mathrm{kg} \mathrm{CO} 2$ eq. per product or regional bioeconomy network can be considered as (un-)sustainable. Rather, in the meanwhile, the planetary boundaries give us an indication on how much a certain planetary boundary is stressed for a specific region, hence how urgent the reduction of regional impacts in this impact category is. This has been adopted as normalization reference in the Environmental Footprint method (Bjørn and Hauschild 2015; Sala et al. 2020) and as DTT weighting factors (Castellani et al. 2016).

\subsubsection{Weighting and aggregation}

In contrast to additive LCSA methods-where separate and different results of S-LCA, E-LCA, and LCC are at the end additively combined by MCDA—-for our SDG oriented HILCSA, we use the relevances of SDG sub-goals given by stakeholders as exogenous weightings of indices on different levels of aggregation (Table 3, Fig. 4). Aggregations reduce complexity of assessments to easier communicate results and to avoid cherry picking (Schmidt-Traub et al. 2017) (analytical-reductionist approach). However, holistic and integrated assessments should be able to manage these complexities as well (systematic-interactionist approach) (Malik 2015), to simplify without curtailing. There are, however, limits to the extent to which indicators should be aggregated into indices. On the one hand, the degree of aggregation depends on the purpose and addressees of the study, so that a balance must be made between the degree of detail required for the greatest possible significance and when this becomes too complex for general comprehensibility. On the other hand, additive links at a high level of aggregation can only be realized, if they do not exhibit linear dependencies, i.e., collinearities leading to double counting (e.g., when SDGs 8.7 and 8.8 if separate).

If more than one normalized indicator rating is classified to an SDG or sub-goal, which is mostly the case, we conduct a linear aggregation by the method of equally weighted averages (Wulf et al. 2017). Afterwards, each of the SDGs and sub-goals has an own score assigned, and so each impact 
category is quantitatively represented by an impact category index. The relevancies of the SDG sub-goals for bioeconomy monitoring (Zeug et al. 2019, 2020) determine the endpoint weightings in our LCIA. A weighted average according to the relevance calculates scores for each of the SDGs and in total for societal needs, provisioning system and PB as end point categories.

\subsection{Interpretation}

In the final phase of interpretation, the aim is twofold: to perform completeness, consistency, sensitivity, and data quality checks (UNEP 2020) as well as to create an as complete and concrete as possible picture of the sustainability of a life cycle. Those results are put in context to an ideal or desirable bioeconomy and the contribution of a regional bioeconomy for implementing the SDGs (Zeug et al. 2020). Risks, chances, synergies, and trade-offs are interpreted and possible conclusions and solutions proposed. It is important to consider that the empirical reality behind indicators can interact with more than one goal, and also can be contradictory to each other or associated with trade-offs. The focus is especially on contradictions and trade-offs between economical, ecological, and social issues; which process steps are relevant for most of the impacts (hotspot analysis and pareto-effects (Halog and Manik 2011)); and to what extent structures of a bioeconomy are sustainable or more sustainable than a (fossil) reference. The data quality of the entire analysis must be considered here with regard to quality of statements, and presented in the results (UNEP 2011).

Dependencies, interlinkages, limitations, and the named shortcomings of LCSAs are discussed and addressed. The previously conducted LCI and LCIA alone leads to a positivist empiricism that alone has very limited ability to address visions and imperatives from a complex sustainability framework. The developed methods, especially the rating and evaluation methods, should be presented to stakeholders to reflect and consolidate them, in particular to calibrate weightings (Suwelack 2016). Moreover, the results should be able to specifically address questions of associated research on governance in context of science-policy interfaces (Gawel et al. 2016), meaning to identify concrete fields of potential action and regulation from the results. The following questions should be addressed by the results and their interpretation: What are the social, economic, and environmental impacts of a regional bioeconomy system? What are the allocated social, economic, and biophysical needs and limits of this bioeconomy system? Which interventions in the system may be able to bring the system within these needs and limits?

By using the SDGs as a framework, it is possible to set the results in context of exiting monitoring activities
(Schmidt-Traub et al. 2017), e.g., national bioeconomy monitorings like SYMOBIO (Bringezu et al. 2020) and the EU biomonitor (BioMonitor 2018). Beyond this, the scientific community in LCSA should strive to established more uniform formats of presenting results, e.g., like Life Cycle Sustainability Dashboards (Traverso et al. 2012).

\section{Discussion}

Regarding the goals and scopes, a regional HILCSA is able of bridging scales (levels): focusing on an assessment of regional bioeconomy as provisioning systems (meso) is able to connect regional (micro) societal needs and the contribution to social SDGs (macro), as well as linking impacts on global environmental and resource systems like planetary boundaries (macro) (micro). This is important, since although strong efforts are made to improve the ecological performance of products at micro level, only a limited to non-existent effect at macro level is achieved yet (Guinée 2016). The environmental-economic significance of LCSAs in this regard can also be shown by the well-known IPAT identity (Common and Stagl 2012). IPAT describes effects on economic growth and environment I (Impact), which are generally dependent on population P (Population), per capita consumption A (Affluence), and production technologies $\mathrm{T}$ (Technology). Previous E-LCAs basically focused on environmental pollution per functional unit of a commodity and thus represent no more than a "super micro" analysis by T (Guinée 2016). Regionalized HILCSA extends this microanalysis to A and I. At this point, however, LCSAs can no longer be sharply and meaningfully separated from political and macroeconomic topics, which was proposed for additive LCSA (cf. (Klöpffer 2008)).

This potential can be further unlocked when quantitative environmental cause and effect chains in regard to absolute sustainability assessment methods are further developed and implemented in LCSA. A sustainable bioeconomy requires that the rate of extraction does not exceed the rate of regeneration and that this regenerativity and the surrounding supporting systems are maintained (Lindqvist et al. 2019). Currently under development are planetary boundary LCIAs (Ryberg et al. 2018) addressing challenges of relating LCIs and LCIAs to operational definitions of planetary boundaries (Robert et al. 2020). This can improve the quality of planetary boundary results in (HI)LCSA significantly. Furthermore, comprehensive material flow data of biomass are not available yet (Adler et al. 2015), but there are extensive efforts for sectoral monitoring (SYMOBIO 2018; Bringezu et al. 2020). For the provisioning system and societal needs, quantitative cause and effect chains are less relevant, also because global modelling is far less possible than for environmental impacts. In this case, it is more important to 
derive qualitative conclusions from a set of quantitative and qualitative indicators and aggregations to support the discussion. Making this linkage of regional assessments and global impacts also clear to regional stakeholders contributes to a more global thinking on a regional level (de Schutter et al. 2019).

It is not only interesting for bioeconomy sector-which is still a marginal sector, especially at the level of consumer goods-to know which specific sustainability a specific product of bioeconomy possesses. Additionally, the sustainability potential that can be tapped by substituting conventional goods with biobased goods, i.e., produced by renewable raw materials and renewable energies, is of strategic interest (Bezama et al. 2017). This is perfectly possible with the presented methods. However, when comparing production systems and their products, the functional unit of mass and volume does not represent the function and use value of products (Sahoo et al. 2019; Zeug et al. 2020). A chair can be made of steel or wood, and we assume that its actual use value is largely independent of the material it is made of. When comparing them in LCSA, the quality of substitution has to be considered: Does a substitute deliver the same use value for the same time? Since a fundamental challenge in provisioning systems is to replace fossil carbon by biogenic carbon (Carus et al. 2020), this substation processes could be assessed by economic-environmental bioeconomy transition indicators currently in development (Jander and Grundmann 2019; Jander et al. 2020; D’Adamo et al. 2020), e.g., fossil resource saving in a sector.

For some readers, it might be remarkable that traditional LCC is not part of HILCSA, instead economic aspects are measured as quality of the provisioning system on a meso and macro scale-mainly by indicators from SoCa, RESPONSA, and SUMINISTRO, covering water, sanitation, energy, working conditions, and mainly consumption and production patterns. Especially for LCC and economic assessments, the goal and scope as well as stakeholders of the study are of decisive importance (Wulf et al. 2017, 2018). Traditional LCC differs notably in conceptual frameworks, terminology, methodology, and content from LCA and has been debated and questioned in sustainability science (Jørgensen et al. 2010; Swarr et al. 2011; Sala et al. 2012a): It focuses on individual costs and benefits of organizations, mostly neglects global perspectives, and there is a systematic bias through monetarization as well as exchange value-constricted valorization (Zeug et al. 2020). We take a systematic and societal approach with a provisioning system addressing society as a whole, taking primarily macro, socio, and ecological economics into account and relating them to the SDGs. Thus, no microeconomic cost accounting like in traditional LCC is adequate.

Additionally, a problem of fundamental character appears in traditional LCC and LCSA, which has not been discussed extensively in previous research yet: to what extent, monetary variables are generally distorted and abstract representations of (non-)material objects, subjects, and their relationships in form of exchange values. In contrast to physical quantities or concrete social outcomes, costs and prices are subject to abstract quantities and substantial fluctuations, not only due to fluctuations in market prices and changing (un-) equilibria of supply and demand. For example, the amount of $\mathrm{CO} 2$ emitted when a certain amount of fuel is burned and subsequent effects on the atmosphere and climate change are almost independent of location and, in the short term, time. Most internalized costs, on the other hand, for one and the same commodity can depend both in real and nominal terms on a number of factors, such as region, currency, and time. They show significant differences (Ciroth 2009), even since accounting procedures themselves are not standardized (Swarr et al. 2011). Besides, solely costs are of secondary importance for production and marketing of commodities in capitalism; instead, the prospect of a return on capital and profit remains paramount (Postone 1993; Zeug et al. 2020; Ciroth 2009), decisive for most economic decisions are not absolute balanced costs, but relative costs of opportunities (Kuosmanen 2005). A challenge will be that not only private industrial actors in capitalist societies have an intrinsic particular interest in capital accumulation and increasing output, and by themselves will not embark to a universal good life for all within planetary boundaries, cost internalization, or the SDGs. Even the SDGs themselves do not deviate from this intrinsic principle (Spangenberg 2017). In this regard and in contrast to the new S-LCA Guidelines (UNEP 2020), we very much question whether "profit" should be a pillar like "people" and "planet" in sustainability assessments (Zeug et al. 2020). Civil society pressuring states are therefore the only entities able to provide the organizational and planning capacity by political coordination necessary for this transition (Hausknost et al. 2017). Corporations are still key actors, but have to be guided by societal rules and strategies in a sustainable bioeconomy. For this, however, a necessary change of patterns of regulation is necessary in a way that states themselves are not depending on abstract economic growth; besides, the latter was identified as a relatively irrelevant objective by stakeholders (Zeug et al. 2019).

In general, we see three main limiting factors in HILCSA:

(i) Data availability: To model the material flows between sectors of a wood fiber-based bioeconomy and so implicitly its products, disaggregation of national flows from I/O models like EXIOBASE (Vendries Algarin et al. 2015; Wood et al. 2014; Lindner et al. 2012; Joshi 1999), EWMFA, and by hybrid LCA (Budzinski et al. 2017) should be considered. This depends also on further I/O database implementation in SoCa and openLCA. Nevertheless, in case studies, it is necessary to fill crucial data gaps by 
own data acquisition by questionnaires and stakeholder or expert interviews. Ideally, this goes hand in hand with establishing common standards for data modeling and exchange for interoperability in LCA (Fritter et al. 2020). Limited data availability will lead to less applicable indicators when HILCSA is applied the first times.

(ii) Weighting and aggregation: The relevancies of SDGs are based on a quite broad stakeholder involvement, expectations, framing of questions, and societal perspectives (Zeug et al. 2019). They are value choices and different individuals; organizations and societies may have different preferences (Andreas et al. 2020). However, this weighting and aggregation as well as normalization methods enables us theoretically to calculate single scores, becoming more acceptable within the LCA community (Andreas et al. 2020), if aspects are neither over nor underrepresent and address multiple issues simultaneously avoiding burden shifting (Lindqvist et al. 2019).

(iii) Measuring a societal change: Sustainability assessments of production systems on a meso level alone are not capable of measuring a necessary societal change. Methods like HILCSA can only support larger macro assessments, like national monitoring of bioeconomy (Bringezu et al. 2020), social science studies on changing and persistent mentalities (Eversberg and Holz 2020) as well as political economy and ecology (Pichler et al. 2020).

\section{Conclusions}

Our analysis shows that the established field of LCAs can be substantially complemented by a HILCSA - which provides a common and integrated sustainability assessment framework applied to regional bioeconomy product systems. Integrating S-LCA, E-LCA, and economic assessments as well as macro and micro approaches is compensating some of their gaps and disadvantages. The proposed set of 109 indicators for HILCSA within the openLCA software environment is capable of addressing societal needs by 21 indicators, the provisioning system by 59 indicators, and the planetary boundaries by 29 indicators. Thereby, HILCSA is capable of addressing 15 out of 17 SDGs (with the exception of SDGs 10 and 17), including all relevant and problematic developing SDGs. In order to achieve this variety of indicators, the LCIA methods ReCiPe, Impact World +, Environmental Footprint 3.0, and SoCa as well as RESPONSA and SUMINISTRO are integrated, and a normalization method by PRP and DTT provides scores which make this variety of different properties and units comparable. Thus, the HILCSA framework addresses to some extend most of the open questions and significant problems of LCSAs in general, in terms of goal and scope, LCI, LCIA, and interpretation. As well as this framework substantiates the idea of an integrated LCSA proposed by Guinée et al. (2011), and shows main advantages compared to additive LCSA, but also makes future research necessary.

As a major value added, we see our LCI and LCIA, which is the first of its kind actually applicable in an existing software environment (openLCA), its linkage to databases, the integration of innovative S-LCA methods as well as overcoming the problem of economic sustainability assessment. In specific and compared to existing rudimentary integrated LCSA approaches, the handling of different kinds of indicators is improved by PRP and DTT methodology, impact categories are unified and comparable by addressing the SDGs, local and global scales are bridged by the SDGs as well as integrating absolute sustainability assessment methods. Not to be neglected as well is the improvement of participation of stakeholders via SDG relevances and further ongoing reflections, in order to ensure their wide recognition and acceptance of their results.

We see important future research needs in validating and applying the HILCSA by case studies on bioeconomy regions, and actual assessments of holistic sustainability and potential of a regional bioeconomy product systems (Zeug et al. 2021). Then, we will be able to address further relevant practical challenges, e.g., detailed definition of system boundaries, sensitivity and uncertainty analyses, and data availability and quality checks. Conducting a series of case studies in HILCSA will not only validate and improve the model itself, but can also help to develop further software environments and databases for LCSA in general. A significant progress will be made, when planetary boundaries are downscaled in a methodically robust manner in the EU to specific regions, provisioning and product systems (Ryberg et al. 2020). The development of a holistic and fully integrated LCIA for LCSA is a promising long-term research objective for meeting possibilities and capabilities of LCSA. But requires extensive cooperation with software developers and LCIA experts, to which as well as to critical discussion, we explicitly invite all interested researchers. Whether transferability of this framework or LCSA in general to other software environments is possible depending on whether basic requirements, such as an activity variable and corresponding databases and LCIAs, are implemented.

Coming back to our point of departure, HILCSA is able to quantify and qualify the (dis-)ability of bioeconomy product systems to address and assess the problem of double decoupling: to achieve as much social outcomes by transgressing as less planetary boundaries as possible, in other words to provide a good life for all within planetary boundaries. By identifying hotspots of unsustainable practices, socioeconomic contradictions and trade-offs when industrial metabolisms are transformed by substitution, specific bioeconomy strategies and action plans can be focused and the subject of governance activities specified. Such sustainability 
assessments are potentially able to structure the discourse around sustainability concepts, the implementation of SDGs and regional transitions to holistic sustainable bioeconomies. A better understanding of what "social," "ecological," and "economic" means can overcome reductionist approaches and epistemological traps and improve the understanding of mutual dependencies and complex interactions. The deployment of local bioeconomies, improving the knowledge base, and linking of local measurements to global goals can support policy makers and underpin policy coherence from a local to international level (European Commission 2018). When advantages of bioeconomies compared to fossil-based economies become clearer, a substitution and transition can be fostered better by all stakeholders, and potential risks can be minimized alongside chances becoming maximized. Such projections thus result in several areas of application, namely the analysis of possible consequences of actions, anticipating problems before they arise, discussing effects of a possible future on the present, and developing an idea of future conditions (Halog and Manik 2011). Additionally, regional bioeconomy practitioner profit from a holistic assessment of their activities and the local and global context they are acting within, when their contribution to global goals gets clear for policymakers and consumers. Beyond that, also civil stakeholders like NGOs and resulting controversial societal discourses profit from an evidence-based method for assessing bioeconomy and establishing a common narrative of a sustainable bioeconomy and sustainable development.

\section{Appendix 1 PRP methodology}

For quantitative indicators $i$ with a high-resolution reference database, the deciles $\left\{q_{1}^{i, r e f} ; \ldots ; q_{9}^{i, \text { ref }}\right\}$, a minimum $q_{\text {min }}^{i, r e f}$, and a maximum $q_{\text {max }}^{i, r e f}$ of $P^{i, r e f}$ are determined and a cumulative distribution function $F\left(x^{i, r e f}\right)$ is generated by regression analyses. This homomorphic representation of the empirical reference is used as a scale. With the determination that $q_{\text {max }}^{i, r e f}$ is the best-practice case in the ref and therefor rated with $r_{\max }^{i}, q_{\min }^{i, r e f}$ is the worst-practice case rated with $r_{\min }^{i}$ and $q_{5}^{i, \text { ref }}$ (median) as an average rated with $r_{q_{5}}^{i}=5$, a scale can be formed by a direct substitution of the statistical measures with the scale $r^{i}$ and $x^{i}$,ref with $x^{i}$ of the case to be evaluated. Thereby from $F\left(x^{i, r e f}\right)$ the continuous rating function $r^{i}\left(x^{i}\right)$ is obtained (Fig. 5). When only partial data is available, then an interpolation and regression is conducted.

In case of qualitative indicators, the shares of its categorical values in the reference, e.g., the percentage of "yes" or "no" answers are applied. Because there is no continuous distribution, it is therefore necessary to develop analogous rating functions from discrete variables. In the simplest case, the presence or non-presence of $i$ in the case is designated as an expression $\theta$, the value of $i$ is $\theta^{i}$ (i.e. $\theta^{i}=1$ or $\theta^{i}=0$ ). It is observed in the reference data that there is a share $p_{\theta=1}^{i}$ of all cases with $\theta^{i}=1$ and another share $p_{\theta=0}^{i}$ with $\theta^{i}=0$, interpreted as the probability $p_{\theta}^{i}$ of $\theta$. The higher $p_{\theta}^{i}\left(p_{\theta}^{i} \rightarrow 1\right)$, the more common $\theta^{i}$ is in reality and therefore to be understood
Fig. 5 Deciles, minimum, maximum, and their values in $\boldsymbol{F}\left(\boldsymbol{x}^{i, r e f}\right)$ of $\mathcal{N}\left(\boldsymbol{x}_{5}^{\text {ref }} ; 1\right)$ and rating function $\boldsymbol{r}^{i}\left(\boldsymbol{x}^{i}\right)$ of quantitative indicators

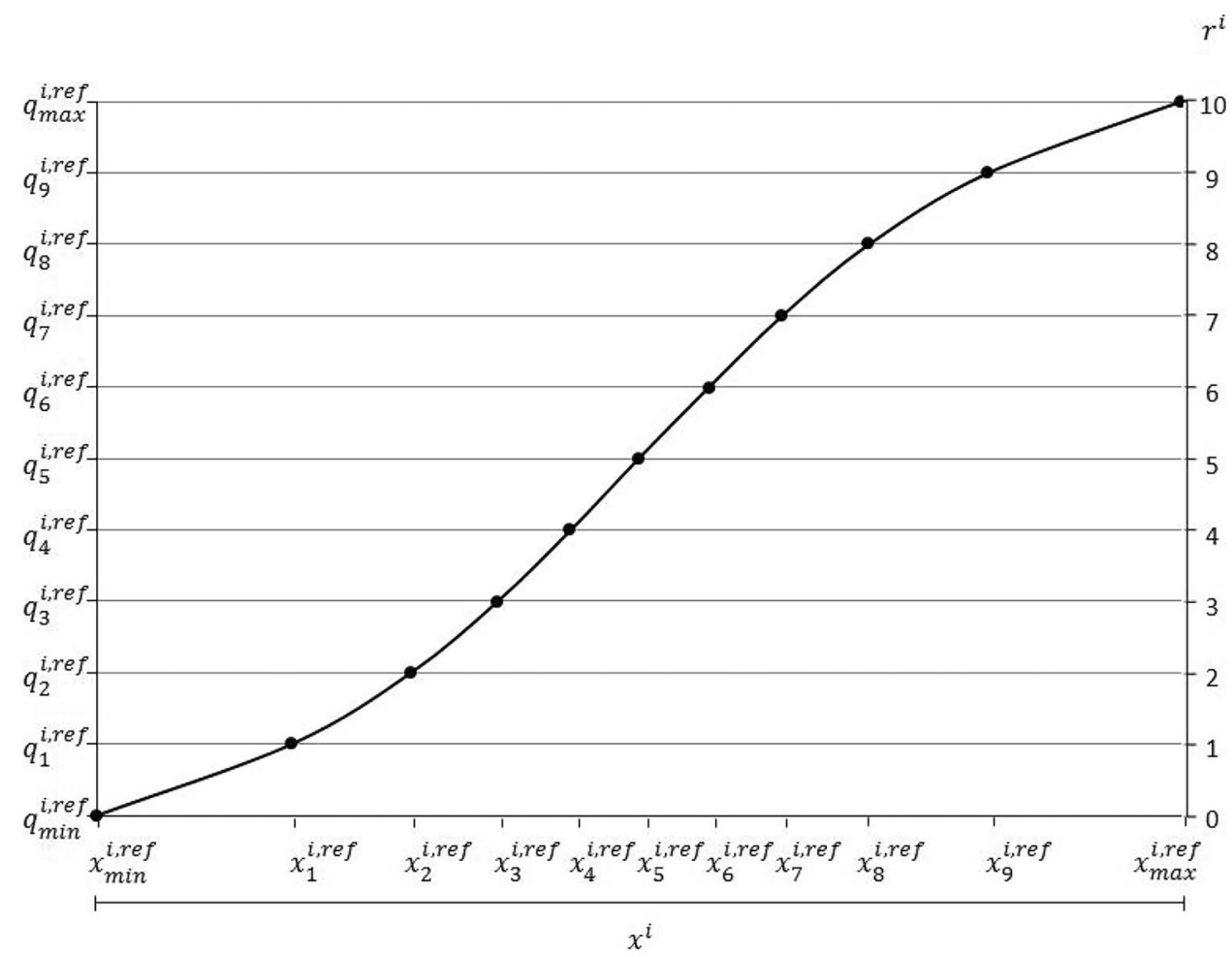


Fig. 6 Rating function $\boldsymbol{r}^{i}\left(p_{\theta}^{i} ; \theta^{i}\right)$ of qualitative indicators

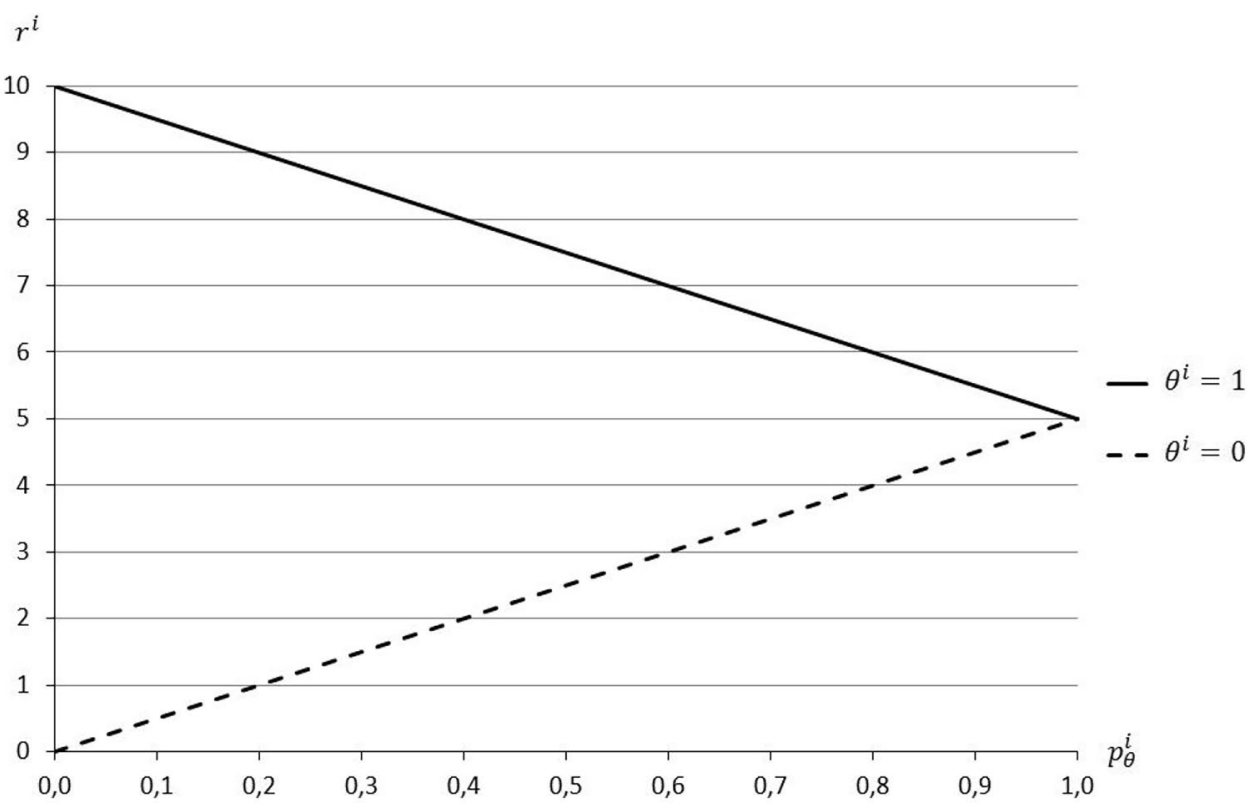

as an average. If $\theta^{i}$ is also the case in the surveyed case, due to the previous determinations, a rating $r^{i}\left(p_{\theta}^{i} \rightarrow 1 ; \theta^{i}\right)=5$ is applied. If $\theta^{i}=1$, but $p_{\theta}^{i}$ is very small, the case represents best practice with $r^{i}\left(p_{\theta=1}^{i} \rightarrow 0 ; \theta^{i}=1\right)=10$. In contrast, $r^{i}\left(p_{\theta=1}^{i} \rightarrow 1 ; \theta^{i}=0\right)=0$ represents worst practice. The evaluation and rating of qualitative indicators is thus determined by $p_{\theta}^{i}$ in the reference and $\theta^{i}$ in the case. In order to obtain rating functions, a linear interpolation between the described characteristic combinations provides the numerical relative (Fig. 6) (Eq. 1)

$r^{i}\left(p_{\theta}^{i}\right)=\left\{\begin{array}{cc}5 p_{\theta}^{i} & \text { if } \theta^{i}=0 \\ -5 p_{\theta}^{i}+10 & \text { if } \theta^{i}=1\end{array}\right.$

If indicators behave in such a way that their increase, stronger expression or qualitative presence is read negative with regard to sustainability, then a transformation is necessary: the result of $r^{i}\left(x^{i}\right)$ and $r^{i}\left(p_{\theta}^{i} ; \theta^{i}\right)$ must be reversed.

Funding Open Access funding enabled and organized by Projekt DEAL.

Open Access This article is licensed under a Creative Commons Attribution 4.0 International License, which permits use, sharing, adaptation, distribution and reproduction in any medium or format, as long as you give appropriate credit to the original author(s) and the source, provide a link to the Creative Commons licence, and indicate if changes were made. The images or other third party material in this article are included in the article's Creative Commons licence, unless indicated otherwise in a credit line to the material. If material is not included in the article's Creative Commons licence and your intended use is not permitted by statutory regulation or exceeds the permitted use, you will need to obtain permission directly from the copyright holder. To view a copy of this licence, visit http://creativecommons.org/licenses/by/4.0/.

\section{References}

Acero AP, Rodríguez C, Ciroth A (2016) LCIA methods-impact assessment methods in life cycle assessment and their impact categories. Green Delta, Berlin

Adler P, Budzinski M, Thrän D (2015) Sachstandsbericht über vorhandene Grundlagen für ein Monitoring der Bioökonomie: Nachhaltigkeit und Ressourcenbasis der Bioökonomie. Forschungszentrum Jülich GmbH, Deutsches Biomasseforschungszentrum (DBFZ), Helmholtz-Zentrum für Umweltforschung (UFZ)

Andreas R, Serenella S, Jungbluth N (2020) Normalization and weighting: the open challenge in LCA. Int J Life Cycle Ass 25:18591865. https://doi.org/10.1007/s11367-020-01790-0

Balkau F, Bezama A (2019) Life cycle methodologies for building circular economy in cities and regions. Waste Manag Res 37:765766. https://doi.org/10.1177/0734242X19864489

Balkau F, Sonnemann G (2017) Synthesis-life cycle approaches and perspectives for sustainable regional development. Life cycle approaches for sustainable regional development. Routledge, New York, pp 322-329

Benoit C, Grießhammer R, Dreyer L, Flysö A, Manhart A, Mazijin B (2006) Feasibility study: integration of social aspects into LCA. Öko-Institut e.V., Freiburg

Bezama A, Ingrao C, O'Keeffe S, Thran D (2019) Resources, collaborators, and neighbors: the three-pronged challenge in the implementation of bioeconomy regions. Sustainability 11:7235. https://doi.org/10.3390/su11247235

Bezama A, Siebert A, Hildebrandt J, Thrän D (2017) Integration of LCA, LCC, and SLCA methods for assessing a bioeconomy region. Life cycle approaches to sustainable regional development. Routledge, New York, pp 258-264

BioMonitor (2018) BioMonitor-monitoring the Bioeconomy. http:// biomonitor.eu/. Accessed 20 December 2018

Bjørn A et al (2020) Review of life-cycle based methods for absolute environmental sustainability assessment and their applications. Environ Res Lett 15:083001. https://doi.org/10.1088/1748-9326/ ab89d7

Bjørn A, Hauschild MZ (2015) Introducing carrying capacity-based normalisation in LCA: framework and development of references 
at midpoint level. Int J Life Cycle Ass 20:1005-1018. https://doi. org/10.1007/s11367-015-0899-2

Bracco S, Tani A, Çalıcıŏ̆lu Ö, Juan MGS, Bogdanski A (2019) Indicators to monitor and evaluate the sustainability of bioeconomy. FAO (Food and Agriculture Organization of the United Nations), Rome. 978-92-5-131796-9

Bringezu S et al (2020) Pilotbericht zum Monitoring der deutschen Bioökonomie. Center for Environmental Systems Research (CESR), Kassel. https://doi.org/10.17170/kobra-202005131255

Budzinski M, Bezama A, Thran D (2017) Monitoring the progress towards bioeconomy using multi-regional input-output analysis: the example of wood use in Germany. J Clean Prod 161:1-11. https://doi.org/10.1016/j.jclepro.2017.05.090

Bulle C et al (2019) IMPACT World plus : a globally regionalized life cycle impact assessment method. Int J Life Cycle Ass 24:16531674. https://doi.org/10.1007/s11367-019-01583-0

Calicioglu Ö, Bogdanski A (2021) Linking the bioeconomy to the 2030 sustainable development agenda: can SDG indicators be used to monitor progress towards a sustainable bioeconomy? New Biotechnol 61:40-49. https://doi.org/10.1016/j.nbt.2020.10.010

Carus M, Dammer L, Raschka A, Skoczinski P, vom Berg C (2020) Renewable carbon-key to a sustainable and future-oriented chemical and plastic industry. nova-Institute, Hürth (Germany)

Castellani V, Benini L, Sala S, Pant R (2016) A distance-to-target weighting method for Europe 2020. Int J Life Cycle Ass 21:1159-1169. https://doi.org/10.1007/s11367-016-1079-8

Chandrakumar C, McLaren SJ (2018a) Exploring the linkages between the environmental sustainable development goals and planetary boundaries using the DPSIR impact pathway framework. In: Benetto E, Gericke K, Guiton M (eds) Designing Sustainable Technologies, Products and Policies. Springer International Publishing, Cham, pp 413-423. https://doi.org/ 10.1007/978-3-319-66981-6_46

Chandrakumar C, McLaren SJ (2018b) Towards a comprehensive absolute sustainability assessment method for effective Earth system governance: defining key environmental indicators using an enhanced-DPSIR framework. Ecol Indic 90:577-583. https://doi.org/10.1016/j.ecolind.2018.03.063

Chandrakumar C, McLaren SJ, Jayamaha NP, Ramilan T (2018) Absolute sustainability-based life cycle Assessment (ASLCA): a benchmarking approach to operate agri-food systems within the $2^{\circ} \mathrm{C}$ global carbon budget. J Ind Ecol 23:906-917. https:// doi.org/10.1111/jiec. 12830

Ciroth A (2009) Cost data quality considerations for eco-efficiency measures. Ecol Econ 68:1583-1590. https://doi.org/10.1016/j. ecolecon.2008.08.005

Ciroth A, Noi CD, Srocka M (2019) Revisiting the activity variable in Social LCA-beyond worker hours. Paper presented at the LCA XIX, Tucson, September 24, 2019

Common M, Stagl S (2012) Ecological economics. Cambridge University Press, Cambridge. https://doi.org/10.1017/cbo9780511805547

Costa D, Quinteiro P, Dias AC (2019) A systematic review of life cycle sustainability assessment: current state, methodological challenges, and implementation issues. Sci Total Environ 686:774-787. https://doi.org/10.1016/j.scitotenv.2019.05.435

Cristobal J, Matos CT, Aurambout JP, Manfredi S, Kavalov B (2016) Environmental sustainability assessment of bioeconomy value chains. Biomass Bioenerg 89:159-171. https://doi.org/10. 1016/j.biombioe.2016.02.002

D'Adamo I, Falcone PM, Imbert E, Morone P (2020) Exploring regional transitions to the bioeconomy using a socio-economic indicator: the case of Italy. Econ Polit-Italy. https://doi.org/10. 1007/s40888-020-00206-4

D'Amato D, Gaio M, Semenzin E (2020) A review of LCA assessments of forest-based bioeconomy products and processes under an ecosystem services perspective. Sci Total Environ 706:135859. https://doi.org/10.1016/j.scitotenv.2019.135859

de Schutter L, Giljum S, Hayha T, Bruckner M, Naqvi A, Omann I, Stagl S (2019) Bioeconomy transitions through the lens of coupled social-ecological systems: a framework for place-based responsibility in the global resource system. SustainabilityBasel 11:5705. https://doi.org/10.3390/su11205705

Di Noi C, Ciroth A (2018) Environmental and social pressures in mining. results from a sustainability hotspots screening. Resources 7:80. https://doi.org/10.3390/resources7040080

Di Noi C, Eisfeldt F, Ciroth A, Bizarro D (2018) Complementarity of social and environmental indicators and risks. An example of the mining industry. Paper presented at the S-LCA 2018, Pescara, September 2018

Dreyer LC, Hauschild MZ, Schierbeck J (2006) A framework for social life cycle impact assessment. Int J Life Cycle Ass 11:8897. https://doi.org/10.1065/lca2005.08.223

EC (2018) A sustainable bioeconomy for Europe: strengthening the connection between economy, society and the environmentupdated bioeconomy strategy. European Commission, Brussels. https://doi.org/10.2777/792130

EC, JRC (2010) Product Environmental Footprint (PEF) Guide. European Commission, Joint Research Centre, Brussels

Eisfeldt F, Rodríguez C, Ciroth A (2017) Life Cycle Sustainability Assessment of photovoltaic panels using soca. In: SETAC Europe 2017, Brussels, 10/05/2017 2017. Green Delta GmbH

Eversberg D, Holz J (2020) Empty promises of growth: the bioeconomy and its multiple reality checks. Working Paper \#2 of the BMBF Junior Research Group "Mentalitites in Flux" (flumen). Friedrich-Schiller-Universität Jena, Jena. https://doi.org/ 10.13140/RG.2.2.30275.84007

Fauzi RT, Lavoie P, Sorelli L, Heidari MD, Amor B (2019) Exploring the current challenges and opportunities of life cycle sustainability assessment. Sustainability 11:636. https://doi.org/ $10.3390 /$ su 11030636

Fazio S, Biganzioli F, De Laurentiis V, Zampori L, Sala S, Diaconu E (2018) Supporting information to the characterisation factors of recommended EF Life Cycle Impact Assessment methods, version 2, from ILCD to EF 3.0 vol EUR 29600 EN. European Commission. https://doi.org/10.2760/002447

Fritter M, Lawrence R, Marcolin B, Pelletier N (2020) A survey of Life Cycle Inventory database implementations and architectures, and recommendations for new database initiatives. Int J Life Cycle Ass 25:1522-1531. https://doi.org/10.1007/ s11367-020-01745-5

Fröhling M, Hiete M (2020) Sustainability and life cycle assessment in industrial biotechnology: a review of current approaches and future needs. In: Fröhling M, Hiete M (eds) Sustainability and Life Cycle Assessment in Industrial Biotechnology. Springer International Publishing, Cham, pp 143-203. https://doi.org/10. 1007/10_2020_122

Gawel E, Purkus A, Pannicke N, Hagemann N (2016) Die Governance der Bioökonomie - Herausforderungen einer Nachhaltigkeitstransformation am Beispiel der holzbasierten Bioökonomie in Deutschland. Helmholtz-Centre for Environmental Research, Leipzig

Guinée J (2016) Life Cycle Sustainability assessment: what is it and what are its challenges? In: Clift R, Druckman A (eds) Taking Stock of Industrial Ecology. Springer International Publishing, Cham, pp 45-68. https://doi.org/10.1007/978-3-319-20571-7_3

Guinee JB et al (2011) Life cycle assessment: past, present, and future. Environ Sci Technol 45:90-96. https://doi.org/10.1021/es101316v

Halog A, Manik Y (2011) Advancing integrated systems modelling framework for life cycle sustainability assessment. Sustainability 3:469-499. https://doi.org/10.3390/su3020469 
Hauschild MZ, Dreyer LC, Jørgensen A (2008) Assessing social impacts in a life cycle perspective-lessons learned. CIRP Ann 57:21-24. https://doi.org/10.1016/j.cirp.2008.03.002

Hausknost D, Schriefl E, Lauk C, Kalt G (2017) A transition to which bioeconomy? An exploration of diverging techno-political choices. Sustainability 9:669. https://doi.org/10.3390/su9040669

Hildebrandt J, Bezama A, Thran D (2020) Insights from the sustainability monitoring tool SUMINISTRO applied to a case study system of prospective wood-based industry networks in Central Germany. Sustainability 12:3896. https://doi.org/10.3390/ su12093896

Hildebrandt J, Budzinski M, Bezama A, O’Keeffe S, Thrän D, Jähkel A (2018a) SUMINISTRO—Sustainability Monitoring Index for assessing regional bio-based Industry Networks. Helmholtz Centre for Environmental Research - UFZ, Leipzig

Hildebrandt J, Budzinski M, Nitzsche R, Weber A, Krombholz A, Thrän D, Bezama A (2019) Assessing the technical and environmental performance of wood-based fiber laminates with lignin based phenolic resin systems. Resour Conserv Recy 141:455464. https://doi.org/10.1016/j.resconrec.2018.10.029

Hildebrandt J, O'Keeffe S, Bezama A, Thrän D (2018b) Revealing the environmental advantages of industrial symbiosis in wood-based bioeconomy networks: an assessment from a life cycle perspective. J Ind Ecol 23:808-822. https://doi.org/10.1111/jiec.12818

Huijbregts MAJ (2016) ReCiPe 2016 - a harmonized life cycle impact assessment method at midpoint and endpoint level report I: characterization. National Institute for Public Health and the Environment, Bilthoven

Huijbregts MAJ et al (2017) ReCiPe2016: a harmonised life cycle impact assessment method at midpoint and endpoint level. Int J Life Cycle Ass 22:138-147. https://doi.org/10.1007/ s11367-016-1246-y

Ingrao $C$ et al (2018) The potential roles of bio-economy in the transition to equitable, sustainable, post fossil-carbon societies: findings from this virtual special issue. J Clean Prod 204:471-488. https://doi.org/10.1016/j.jclepro.2018.09.068

Jander W, Grundmann P (2019) Monitoring the transition towards a bioeconomy: a general framework and a specific indicator. $\mathbf{J}$ Clean Prod 236:117564. https://doi.org/10.1016/j.jclepro.2019. 07.039

Jander W, Wydra S, Wackerbauer J, Grundmann P, Piotrowski S (2020) Monitoring bioeconomy transitions with economic-environmental and innovation indicators: addressing data gaps in the short term. Sustainability 12:4683. https://doi.org/10.3390/su12114683

Jarosch L, Zeug W, Bezama A, Finkbeiner M, Thran D (2020) A regional socio-economic life cycle assessment of a bioeconomy value chain. Sustainability 12. https://doi.org/10.3390/su12031259

Jørgensen A, Finkbeiner M, Jørgensen MS, Hauschild MZ (2010) Defining the baseline in social life cycle assessment. Int J Life Cycle Ass 15:376-384. https://doi.org/10.1007/ s11367-010-0176-3

Joshi S (1999) Product environmental life-cycle assessment using input-output techniques. J Ind Ecol 3:95-120. https://doi.org/ $10.1162 / 108819899569449$

Keller H, Rettenmaier N, Reinhardt GA (2015) Integrated life cycle sustainability assessment-a practical approach applied to biorefineries. Appl Energy 154:1072-1081. https://doi.org/10.1016/j. apenergy.2015.01.095

Kloepffer W (2008) Life cycle sustainability assessment of products. Int J Life Cycle Ass 13:89-95. https://doi.org/10.1065/lca2008.02.376

Kuosmanen T (2005) Measurement and analysis of eco-efficiency-an economist's perspective. J Ind Ecol 9:15-18. https://doi.org/10. $1162 / 108819805775248025$

Lindner S, Legault J, Guan D (2012) Disaggregating input-output models with incomplete information. Econ Syst Res 24:329-347. https://doi.org/10.1080/09535314.2012.689954
Lindqvist AN, Broberg S, Tufvesson L, Khalil S, Prade T (2019) Biobased production systems: why environmental assessment needs to include supporting systems. Sustainability 11:4678. https:// doi.org/10.3390/su11174678

Linser S, Lier M (2020) The contribution of sustainable development goals and forest-related indicators to national bioeconomy progress monitoring. Sustainability 12:2898. https://doi.org/10. 3390/su12072898

Lyytimaki J, Salo H, Lepenies R, Buttner L, Mustajoki J (2020) Risks of producing and using indicators of sustainable development goals. Sustain Dev 28:1528-1538. https://doi.org/10.1002/sd. 2102

Malik F (2015) Strategie des Managements komplexer Systeme. Haupt Verlag, Bern

Manfredi S, Allacker K, Pelletier N, Schau E, Chomkhamsri K, Pant R, Pennington D (2015) Comparing the European Commission product environmental footprint method with other environmental accounting methods. Int J Life Cycle Ass 20:389-404. https:// doi.org/10.1007/s11367-014-0839-6

O’Neill DW, Fanning AL, Lamb WF, Steinberger JK (2018) A good life for all within planetary boundaries. Nat Sustain 1:88-95. https://doi.org/10.1038/s41893-018-0021-4

O'Keeffe S, Majer S, Bezama A, Thrän D (2016) When considering no man is an island-assessing bioenergy systems in a regional and LCA context: a review. Int J Life Cycle Ass 21:885-902. https:// doi.org/10.1007/s11367-016-1057-1

OECD (2018) Meeting policy challenges for a sustainable bioeconomy. OECD Publishing, Paris. https://doi.org/10.1787/ 9789264292345-en

Onat NC, Kucukvar M, Halog A, Cloutier S (2017) Systems thinking for life cycle sustainability assessment: a review of recent developments, applications, and future perspectives. Sustainability 9:706. https://doi.org/10.3390/su9050706

Parrique TBJ, Briens F, Kerschner C, Kraus-Polk A, Kuokkanen A, Spangenberg JH (2019) Decoupling debunked-evidence and arguments against green growth as a sole strategy for sustainability. The European Environmental Bureau, Brussels

Pichler M, Brand U, Görg C (2020) The double materiality of democracy in capitalist societies: challenges for social-ecological transformations. Env Polit 29:193-213. https://doi.org/10.1080/ 09644016.2018 .1547260

Postone M (1993) Time, labor, and social domination. Cambridge University Press, New York

Prado V, Rogers K, Seager TP (2012) Integration of MCDA tools in valuation of comparative life cycle assessment. In: Life Cycle Assessment Handbook. pp 413-431. https://doi.org/10.1002/ 9781118528372.ch19

Ramcilovic-Suominen S, Pülzl H (2018) Sustainable development-a 'selling point' of the emerging EU bioeconomy policy framework? J Clean Prod 172:4170-4180. https://doi.org/10.1016/j. jclepro.2016.12.157

Robert N et al (2020) Development of a bioeconomy monitoring framework for the European Union: an integrative and collaborative approach. N Biotechnol 59:10-19. https://doi.org/10.1016/j.nbt. 2020.06 .001

Ryberg MW, Owsianiak M, Richardson K, Hauschild MZ (2018) Development of a life-cycle impact assessment methodology linked to the Planetary Boundaries framework. Ecol Indic 88:250-262. https://doi.org/10.1016/j.ecolind.2017.12.065

Ryberg MW, Andersen MM, Owsianiak M, Hauschild MZ (2020) Downscaling the planetary boundaries in absolute environmental sustainability assessments - a review Journal of Cleaner Production 276:123287. https://doi.org/10.1016/j.jclepro.2020.123287

Sahoo K, Bergman R, Alanya-Rosenbaum S, Gu HM, Liang SB (2019) Life cycle assessment of forest-based products: a review. Sustainability 11:4722. https://doi.org/10.3390/su11174722 
Sala S, Castellani V (2019) The Consumer Footprint: monitoring sustainable development goal 12 with process-based life cycle assessment. J Clean Prod 240:118050. https://doi.org/10.1016/j. jclepro.2019.118050

Sala S, Crenna E, Secchi M, Sanye-Mengual E (2020) Environmental sustainability of European production and consumption assessed against planetary boundaries. J Environ Manage 269:110686. https://doi.org/10.1016/j.jenvman.2020.110686

Sala S, Farioli F, Zamagni A (2012a) Life cycle sustainability assessment in the context of sustainability science progress (part 2). Int J Life Cycle Ass 18:1686-1697. https://doi.org/10.1007/ s11367-012-0509-5

Sala S, Farioli F, Zamagni A (2012b) Progress in sustainability science: lessons learnt from current methodologies for sustainability assessment: Part 1. Int J Life Cycle Ass 18:1653-1672. https:// doi.org/10.1007/s11367-012-0508-6

Schmidt-Traub G, Kroll C, Teksoz K, Durand-Delacre D, Sachs JD (2017) National baselines for the Sustainable Development Goals assessed in the SDG Index and Dashboards. Nat Geosci 10:547+. https://doi.org/10.1038/Ngeo2985

Siebert A, Bezama A, O'Keeffe S, Thran D (2018a) Social life cycle assessment indices and indicators to monitor the social implications of wood-based products. J Clean Prod 172:4074-4084. https://doi.org/10.1016/j.jclepro.2017.02.146

Siebert A, Bezama A, O'Keeffe S, Thrän D (2016) Social life cycle assessment: in pursuit of a framework for assessing wood-based products from bioeconomy regions in Germany. Int $\mathrm{J}$ Life Cycle Ass 23:651-662. https://doi.org/10.1007/s11367-016-1066-0

Siebert A, O'Keeffe S, Bezama A, Zeug W, Thrän D (2018b) How not to compare apples and oranges: generate context-specific performance reference points for a social life cycle assessment model. J Clean Prod 198:587-600. https://doi.org/10.1016/j. jclepro.2018.06.298

Smetana S, Tamásy C, Mathys A, Heinz V (2016) Measuring Relative Sustainability of Regions Using Regional Sustainability Assessment Methodology. Geogr Anal 48:391-410. https://doi.org/10. 1111 /gean. 12102

Spangenberg JH (2017) Hot air or comprehensive progress? A critical assessment of the SDGs. Sustain Dev 25:311-321. https://doi. org/10.1002/sd.1657

Suwelack K (2016) Conversion technology and life cycle assessment of renewable resources. Hohenheim University, Hohenheim

Swarr TE, Hunkeler D, Klopffer W, Pesonen HL, Ciroth A, Brent AC, Pagan R (2011) Environmental life-cycle costing: a code of practice. Int J Life Cycle Ass 16:389-391. https://doi.org/10.1007/ s11367-011-0287-5

SYMOBIO (2018) Systematic monitoring and modeling of the bioeconomy. https://symobio.de/en/start_en. Accessed 05 January 2018

Taylor PG, Abdalla K, Quadrelli R, Vera I (2017) Better energy indicators for sustainable development. Nat Energy 2:17117. https:// doi.org/10.1038/nenergy.2017.117

Traverso M, Finkbeiner M, Jorgensen A, Schneider L (2012) Life Cycle Sustainability Dashboard. J Ind Ecol 16:680-688. https://doi.org/ 10.1111/j.1530-9290.2012.00497.x

Troullaki K, Rozakis S, Kostakis V (2021) Bridging barriers in sustainability research: a review from sustainability science to life cycle sustainability assessment. Ecol Econ 184:107007. https://doi.org/ 10.1016/j.ecolecon.2021.107007

EU (2015) Closing the loop - An EU action plan for the Circular Economy. European Commission, Brussels

UN, (2015) Transforming our world: the 2030 Agenda for Sustainable Development. United Nations, New York

UN, (2019) The Sustainable Development Goals Report. United Nations, New York
UNEP (2011) Towards a life cycle sustainability assessment—making informed choices on products. UNEP/SETAC Life Cycle Initiative

UNEP (2020) Guidelines for social life cycle assessment of products and organizations. United Nations Environment Programme (UNEP)

Urban K et al (2018) Markets, sustainability management and entrepreneurship. In: Lewandowski I (ed) Bioeconomy. Springer International Publishing, Cham, pp 231-286. https://doi.org/10.1007/ 978-3-319-68152-8_8

Valdivia S, Ugaya CML, Hildenbrand J, Traverso M, Mazijn B, Sonnemann G (2012) A UNEP/SETAC approach towards a life cycle sustainability assessment-our contribution to Rio+20. Int J Life Cycle Ass 18:1673-1685. https://doi.org/10.1007/ s11367-012-0529-1

Vendries Algarin J, Hawkins TR, Marriott J, Scott Matthews H, Khanna V (2015) Disaggregating the power generation sector for input-output life cycle assessment. J Ind Ecol 19:666-675. https://doi.org/10.1111/jiec.12207

Weidema BP, Goedkoop M (2019) A Life Cycle impact pathway framework for the SDGs. Paper presented at the Presentation for the LCM2019, Poznan, 1-4 September 2019

Weimar H (2015) The wood fibre equivalent [m3 (f)]—an introduction. In: Second Meeting of the UNECE/FAO Team of Specialists on Forest Products Statistics, Geneva, 17 March 2015

Wood R, Hawkins TR, Hertwich EG, Tukker A (2014) Harmonising national input-output tables for consumption-based accounting-experiences from Exiopol. Econ Syst Res 26:387-409. https://doi.org/10.1080/09535314.2014.960913

Wulf C, Werker J, Ball C, Zapp P, Kuckshinrichs W (2019) Review of sustainability assessment approaches based on life cycles. Sustainability 11:5717. https://doi.org/10.3390/su11205717

Wulf C, Werker J, Zapp P, Schreiber A, Schlör H, Kuckshinrichs W (2018) Sustainable Development Goals as a guideline for indicator selection in life cycle sustainability assessment. Procedia CIRP 69:59-65. https://doi.org/10.1016/j.procir.2017.11.144

Wulf C, Zapp P, Schreiber A, Marx J, Schlor H (2017) Lessons learned from a life cycle sustainability assessment of rare earth permanent magnets. J Ind Ecol 21:1578-1590. https://doi.org/10.1111/ jiec. 12575

Zamagni A, Amerighi O, Buttol P (2011) Strengths or bias in social LCA? Int J Life Cycle Ass 16:596-598. https://doi.org/10.1007/ s11367-011-0309-3

Zamagni A, Pesonen HL, Swarr T (2013) From LCA to life cycle sustainability assessment: concept, practice and future directions. Int J Life Cycle Ass 18:1637-1641. https://doi.org/10.1007/ s11367-013-0648-3

Zeug W, Bezama A, Moesenfechtel U, Jähkel A, Thrän D (2019) Stakeholders' interests and perceptions of bioeconomy monitoring using a sustainable development goal framework. Sustainability 11:1511. https://doi.org/10.3390/su11061511

Zeug W, Bezama A, Thrän D (2020) Towards a holistic and integrated life cycle sustainability assessment of the bioeconomy-background on concepts, visions and measurements vol 07. Helmholtz-Centre for Environmental Research (UFZ), Leipzig. https://doi.org/10.13140/ RG.2.2.16912.02564

Zeug W, Bezama A, Thrän D (2021) Application of holistic and integrated LCSA: case study on laminated veneer lumber production in Central Germany. Forthcoming

Zimek M, Schober A, Mair C, Baumgartner RJ, Stern T, Füllsack M (2019) The third wave of lca as the "decade of consolidation." Sustainability 11:3283. https://doi.org/10.3390/su11123283

Publisher's Note Springer Nature remains neutral with regard to jurisdictional claims in published maps and institutional affiliations. 